\title{
A Hail Growth Trajectory Model for Exploring the Environmental Controls on Hail Size: Model Physics and Idealized Tests
}

\author{
MATTHEW R. KumJiAn AND KeLly LOMBARDO \\ Department of Meteorology and Atmospheric Science, The Pennsylvania State University, University Park, Pennsylvania
}

(Manuscript received 17 January 2020, in final form 29 May 2020)

\begin{abstract}
A detailed microphysical model of hail growth is developed and applied to idealized numerical simulations of deep convective storms. Hailstone embryos of various sizes and densities may be initialized in and around the simulated convective storm updraft, and then are tracked as they are advected and grow through various microphysical processes. Application to an idealized squall line and supercell storm results in a plausibly realistic distribution of maximum hailstone sizes for each. Simulated hail growth trajectories through idealized supercell storms exhibit many consistencies with previous hail trajectory work that used observed storms. Systematic tests of uncertain model parameters and parameterizations are performed, with results highlighting the sensitivity of hail size distributions to these changes. A set of idealized simulations is performed for supercells in environments with varying vertical wind shear to extend and clarify our prior work. The trajectory calculations reveal that, with increased zonal deep-layer shear, broader updrafts lead to increased residence time and thus larger maximum hail sizes. For cases with increased meridional low-level shear, updraft width is also increased, but hailstone sizes are smaller. This is a result of decreased residence time in the updraft, owing to faster northward flow within the updraft that advects hailstones through the growth region more rapidly. The results suggest that environments leading to weakened horizontal flow within supercell updrafts may lead to larger maximum hailstone sizes.
\end{abstract}

\section{Introduction}

Hailstorms are becoming an increasingly costly socioeconomic hazard, producing billions of dollars in damages annually in the United States (Gunturi and Tippett 2017), and occasionally leading to injuries and fatalities (e.g., Changnon et al. 2009; Picca and Ryzhkov 2012; Kahraman et al. 2016). In part, the damage and casualty potential is influenced by the size and quantity of hailstones. Because of the risk posed by damaging hailstorms, the U.S. Storm Prediction Center and National Weather Service local offices provide forecasts and warnings for "severe" ( $\geq 1$ in. or $2.5 \mathrm{~cm}$ in maximum dimension) hail, respectively.

Unfortunately, despite the frequent occurrence and significant socioeconomic threat of hailstorms, operational forecasting and detection of hail size remains challenging (e.g., Blair et al. 2011, 2017; Ortega 2018). These operational challenges arise partly owing to a lack of a fundamental understanding of which environments lead to storms that produce hail of given size. For example,

Corresponding author: Matthew R. Kumjian, kumjian@psu.edu previous climatologies have investigated the relationship between hail size and commonly used bulk severe weather indices like CAPE and found that these indices exhibit little-to-no skill in predicting hail size (e.g., Edwards and Thompson 1998; Jewell and Brimelow 2009; Johnson and Sugden 2014). Several recent studies have also explored the relationship between hail size categories and environmental parameters in Europe. Púčik et al. (2015) examined a large dataset of severe event proximity soundings across Europe for severe $(>2 \mathrm{~cm})$ and significantly severe $(>5 \mathrm{~cm})$ hail size categories. They found a shift toward increased CAPE and increased deep-layer shear for the larger hail category, albeit with significant overlap of the distribution of environmental parameter values. They also found that, for any combination of CAPE and deep-layer shear, increasing lifting condensation level (LCL) height tended to further increase the probability of large hail. The increase in large hail probability with LCL height echoed earlier results from Groenemeijer and van Delden (2007) and Kaltenböeck et al. (2009), and may be related to increased updraft width with increasing LCL and/or level of free convection (LFC) height (e.g., McCaul and Cohen 2002). 
In a similar study, Taszarek et al. (2017) found consistent results, where the probability of large hail increased with greater instability, deep-layer shear, and higher LCL height. Using reanalysis data, Rädler et al. (2018) built a simple statistical model based on instability and deep-layer shear to predict the occurrence of severe hazards, including hail, that was able to reasonably reproduce observed hail climatological features in Europe. In addition, the community is only beginning to recognize different "flavors" of hail threats and to identify their distinguishing features on radar displays or from environmental cues, including storms that produce large amounts of small hail (e.g., Kalina et al. 2016; Wallace et al. 2018; Kumjian et al. 2019; Friedrich et al. 2019) or those that produce giant or gargantuan hail (Blair et al. 2011; Gutierrez and Kumjian 2018; Kumjian et al. 2020). Conceptual models for why or how these storms produce these distinct types of hail threats do not exist.

Another major challenge plaguing hail science is the poor quality of the severe hail reports database, which contains a number of known biases including population density, sizing to reference objects, and the change of the criterion for "severe" hail by the U.S. National Weather Service (e.g., Allen and Tippett 2015; Ortega 2018). More recently, there have been reports of roofing contractors calling in false or inflated hail-size reports to gin up business (I. Giammanco 2018, personal communication). To avoid these issues, some studies use radarbased algorithms like the maximum estimated size of hail (MESH; Witt et al. 1998) for climatologies (Cintineo et al. 2012) or "ground truth" of hail forecast systems (Gagne et al. 2017), but MESH shows little correlation to maximum hail size and is better suited simply as a hail detection tool (Ortega 2018; Murillo and Homeyer 2019). Similarly, radar-based vertically integrated liquid (VIL) or VIL density (VILD) show little skill at determining hail size (Edwards and Thompson 1998). A recent assessment also determined that satellite-based and lightning metrics provide little practical skill for determining hail size, or even discriminating severe and nonsevere hail cases (e.g., Murillo and Homeyer 2019).

Here, we adopt a different approach to exploring how environmental factors affect hail production in storms: simulated hailstone growth trajectories. Studies of hailstone trajectories have a rich history in the literature (e.g., Browning and Foote 1976; Heymsfield 1983; Miller and Fankhauser 1983; Nelson 1983; Ziegler et al. 1983; Heymsfield 1983; Foote 1984; Musil et al. 1986; Rasmussen and Heymsfield 1987b; Miller et al. 1988, 1990; Tessendorf et al. 2005, among many others) and have led to substantial improvements in our understanding of hail growth processes in convective storms. Though providing important insights into hail physics, such trajectory calculations typically have been run on observed storm cases, and thus have not been directly used in forecasts. More recently, however, simplified one-dimensional hail trajectories (e.g., Brimelow et al. 2002) have been implemented to run in convection-allowing models to provide estimates of hail size (Adams-Selin and Ziegler 2016, hereafter ASZ16).

Early studies of hail growth in convective storms heavily relied on radar observations (e.g., Browning 1964; Dennis et al. 1970; Browning and Foote 1976; Chalon et al. 1976; Browning 1977) to infer airflow patterns and precipitation particle trajectories. These detailed studies deduced that hail embryos were supplied on the fringes of the updraft (sometimes termed the "embryo curtain") and established the importance of the storm-relative winds and airflow patterns within the storm. The seminal work of Browning and Foote (1976) and review by Browning (1977) present a conceptual model for embryo source regions, airflow patterns in the storm, and pathways such that hailstones grow in a single pass through the updraft in a simple upand-down trajectory.

Later hailstone trajectory computations using growth models of varying complexity verified the importance of storm-relative winds for embryo injection into the main updraft (e.g., Heymsfield et al. 1980; Nelson 1983). Many of these studies supported the conceptual model of Browning and Foote (1976) and found simple updown trajectories, with no suggestions of hailstone "recycling" or repeated large vertical excursions through the updraft ${ }^{1}$ (e.g., Ziegler et al. 1983; Nelson 1983; Foote 1984; Rasmussen and Heymsfield 1987b; Miller et al. 1990). Additionally, several of these studies identified the importance of the mesocyclone for hailstone pathways across the updraft in supercells (e.g., Nelson 1983; Miller et al. 1988; Tessendorf et al. 2005). The mesocyclone plays a crucial role in the growth of large hail by allowing the hailstone to remain in the hail growth region and pass into regions of stronger updraft as it grows, maintaining a balance between the hailstone fall speed and updraft speed (e.g., Nelson 1983; Ziegler et al. 1983; Heymsfield 1983; Foote 1984; Rasmussen and Heymsfield 1987b). The resulting trajectories through the updraft are rather flat and, if projected onto a horizontal plane, follow cyclonically curved paths (Nelson 1983; Heymsfield 1983; Foote 1984; Rasmussen and Heymsfield 1987b; Miller et al. 1988, 1990). These results largely agree with the conceptual model of Browning and Foote (1976) and

\footnotetext{
${ }^{1}$ Unfortunately, this unfounded "recycling" idea is still perpetuated in popular media and textbooks.
} 
are supported by analysis of hailstone water isotope content by Federer et al. (1982). Additional factors identified as important for the growth of large hail include updraft width (e.g., Nelson 1983; Ziegler et al. 1983; Foote 1984; Nelson 1987; Dennis and Kumjian 2017, hereafter DK17) and slow horizontal airflow within the updraft (Rasmussen and Heymsfield 1987b), which can act to increase residence time in the hail growth region (Heymsfield 1983; Foote 1984).

Here, we adopt similar hailstone growth trajectory calculations, but with novel changes. For example, we run the trajectories through full 3D storm simulations, rather than relying on dual-Doppler analyses as in many of the past studies. An advantage of using simulated storms is that all kinematic, thermodynamic, and microphysical fields are consistent with one another (within the framework of the model). Previous studies required assumptions about in-cloud conditions (e.g., Ziegler et al. 1983; Nelson 1983; Rasmussen and Heymsfield 1987b, among many others) and did not consider uncertainty or errors in updraft speeds, which can be significant $(>50 \%)$ in dual-Doppler analyses aloft in deep convective storms (e.g., Potvin et al. 2012b,a). The approach adopted here also allows for exploration of a large parameter space of environments untethered to a particular case study or dataset. Additionally, improved computing power allows for very large numbers of trajectories to be computed for each storm, which is useful for generating more robust statistics on hail production.

Of course, such trajectory calculations have their own limitations. We rely on the model to faithfully represent realistic storm structures for a given environment. The microphysics schemes producing the cloud water fields in such simulations are clearly simplifications; given a lack of in situ observations, however, such simulations are effectively the state of the art and are widely used for a range of operational and research purposes. The hail growth model we develop here also has numerous tunable parameters, the sensitivity to which we will explore in the appendix. However, this framework and all its potential biases and uncertainties will be consistent across all simulations and thus allows for exploring a large parameter space of severe storm environments. The next section provides a detailed description of the microphysical growth model. Idealized tests are performed and their results described in section 3. The paper closes with a discussion of the main conclusions in section 4 .

\section{Hail growth trajectory model description}

The hailstone trajectories are driven through idealized, three-dimensional storms, which are simulated using Cloud Model 1 (CM1; Bryan and Fritsch 2002) with the Morrison two-moment bulk microphysics scheme (Morrison et al. 2005, 2009) with "hail" as the rimed ice. Note that the trajectory model described here is general enough to be used with any bulk microphysics scheme that prognoses hydrometeor mass mixing ratios, with care taken to account for any scheme-dependent implicit assumptions about the hydrometeor size distributions. Thus, the 3D storm-relative airflow patterns, thermodynamic fields, and in-storm cloud and precipitation content are determined by the CM1 simulation. The hailstones are advected by the 3D wind field in a purely Lagrangian manner using a 1-s time step; at each time step, microphysical calculations are performed using CM1 output from the grid box in which the hailstone is located, and hailstone mass, size, and fall speed are updated. For this study, the 3D simulation is not updated (i.e., no microphysical or thermodynamic feedbacks from the hail trajectory calculations) and the storm is assumed to be in steady state, following all of the previous studies described above. (The impact of an evolving storm on hail production is explored in a forthcoming paper.) This setup is similar to our previous work (DK17), except here we explicitly calculate the microphysical processes and thermal energy balance for the growing spherical hailstones with a detailed model that is described in the subsections below. We note that melting is not considered, as it is not a major factor for the larger $(>2 \mathrm{~cm})$ hail of interest in this study (e.g., Ryzhkov et al. 2013a,b). Hail smaller than this substantially or entirely melts on its descent to the surface. Future versions of the trajectory model will include a detailed melting scheme following Rasmussen and Heymsfield (1987a).

\section{a. Fall speeds}

The hailstone terminal velocity $v_{h}$ follows an expression used in bulk microphysics schemes (e.g., Morrison et al. 2005, 2009) that is derived from the balance between gravity and the drag force for spherical particles:

$$
v_{h}=\sqrt{\frac{4 \rho_{h} D_{h} g}{3 \rho_{a, 0} C_{D}}}\left(\frac{\rho_{a, 0}}{\rho_{a}}\right)^{0.5},
$$

where $\rho_{h}$ is the hailstone density, $\rho_{a, 0}$ is the reference air density at a pressure of $1000 \mathrm{hPa}$, and $\rho_{a}$ is the air density at the level of interest (for the air density correction to fall speeds), $g$ is the gravitational acceleration, $D_{h}$ is the hailstone diameter, and $C_{D}$ is the drag coefficient. The drag coefficient is set to 0.5 for these tests, based on data reported in Heymsfield and Wright (2014), and Heymsfield et al. (2014, 2018). The sensitivity of the growth trajectory calculations to $C_{D}$ is presented in the appendix. 
The mass-weighted fall speed of raindrops $v_{q_{r}}$ is computed using the raindrop size distribution at each grid box produced by the microphysics parameterization scheme, and the empirical fall speed-diameter relationship from Brandes et al. (2002):

$$
\begin{aligned}
v_{q_{r}}= & -0.1021+4.932 D_{r}-0.9551 D_{r}^{2}+0.07934 D_{r}^{3} \\
& -0.002362 D_{r}^{4},
\end{aligned}
$$

where $D_{r}$ is the raindrop equivalent volume diameter in $\mathrm{mm}$ and $v_{q_{r}}$ is in $\mathrm{ms}^{-1}$. Cloud droplets, cloud ice crystals, and snow are assumed to have negligible fall speeds relative to the hailstones.

\section{b. Collection of supercooled liquid water}

The model accounts for continuous collection of supercooled cloud droplets and raindrops. The collection efficiency for cloud droplets $E_{\mathrm{cc}}$ is parameterized based on the mean-mass cloud droplet diameter $D_{m \text {,cloud }}$ determined from the CM1 storm simulation, assuming an exponential size distribution:

$$
D_{m, \text { cloud }}=\left(\frac{6 \rho_{a} q_{c}}{N_{c} \pi \rho_{\ell}}\right)^{1 / 3},
$$

where $q_{c}$ and $N_{c}$ are the cloud droplet mass mixing ratio $\left(\mathrm{kg} \mathrm{kg}^{-1}\right)$ and number concentration $\left(\mathrm{m}^{-3}\right)$ from the bulk microphysics scheme, and $\rho_{\ell}$ is the density of liquid water $\left(\mathrm{kg} \mathrm{m}^{-3}\right)$. The value of $E_{\mathrm{cc}}$ is unity for $D_{m \text {,cloud }}>5 \mu \mathrm{m}$; at $5 \mu \mathrm{m}$, the collection efficiency is set to 0.1 and tapers to zero linearly with

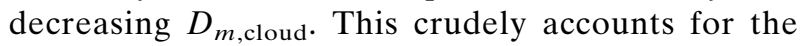
lower (but nonzero) collision efficiencies of tiny, low-inertia droplets that follow streamlines around larger particles (e.g., Lamb and Verlinde 2011). The sensitivity to this parameterization is explored in the appendix.

The importance of collection of supercooled raindrops for hail growth is essentially unknown. Some previous studies have ignored it entirely (e.g., ASZ16), citing low raindrop concentrations and thus unlikely collisions with hailstones. However, portions of the updrafts of deep convective storms are known to contain raindrops, often observed with dual-polarization radar as differential reflectivity $\left(Z_{\mathrm{DR}}\right)$ columns (see Kumjian et al. 2014, and references therein) and specific differential phase $\left(K_{\mathrm{DP}}\right)$ columns (van Lier-Walqui et al. 2016). Unlike low-inertia cloud droplets, raindrops have significant inertia and thus are unlikely to follow streamlines around hailstones. Thus, collisions, though perhaps infrequent, are likely to occur in some regions of the hail growth zone within the updraft. We suggest that such collisions may lead to splashing, such that not all liquid water is collected. As such, we anticipate a collection efficiency below unity. Owing to the relatively smaller concentrations of raindrops compared to cloud droplets, collection is likely more stochastic than continuous. In the absence of detailed information, however, we assume continuous collection. Future work should investigate how treating a spectrum of rain sizes and fall speeds and the more discrete nature of raindrophailstone collisions affects the overall hail growth rates. Though of secondary importance to collection of cloud droplets, collection of rain, which likely strongly depends on the raindrop size distribution, is found to be nonnegligible in these calculations (see the appendix). There are no published raindrop-hailstone collision or collection efficiencies, either, so we set the latter somewhat arbitrarily to 0.8 . Sensitivity tests for this parameter are shown in appendix.

The mass growth rate owing to accretion of supercooled liquid water is given by

$$
\left(\frac{d m}{d t}\right)_{\mathrm{accr}}=\frac{\pi D_{h}^{2}}{4} \omega_{c} E_{\mathrm{cc}} v_{h}+\frac{\pi D_{h}^{2}}{4} \omega_{r} E_{\mathrm{cr}}\left(v_{h}-v_{q_{r}}\right)
$$

where the first term on the right-hand side is cloud droplet collection and the second is raindrop collection, $\omega_{c}$ and $\omega_{r}$ are the cloud droplet and raindrop liquid water contents, respectively, and $E_{\mathrm{cc}}$ and $E_{\mathrm{cr}}$ are the cloud droplet and raindrop collection efficiencies, respectively.

If the hailstone surface temperature $T_{\text {sfc }}<273.15 \mathrm{~K} \equiv$ $T_{0}$, the hailstone is in the dry growth regime. As such, $100 \%$ of the accreted liquid is frozen. The density of the accumulated rime $\rho_{\text {rime }}\left(\mathrm{kg} \mathrm{m}^{-3}\right)$ is calculated following an adaptation of the Heymsfield and Pflaum (1985) parameterization:

$$
\rho_{\text {rime }}=300 A^{0.44}
$$

if $A \geq 1.60$, or if $A<1.60$ and $T_{\text {sfc }}<-5^{\circ} \mathrm{C}$, and

$$
\begin{aligned}
\rho_{\text {rime }}= & 1000.0 \exp (-0.03115-1.7030 A \\
& \left.+0.9116 A^{2}-0.1224 A^{3}\right)
\end{aligned}
$$

otherwise. In Eqs. (5) and (6),

$$
A\left(\mu \mathrm{m} \mathrm{m} \mathrm{s}^{-1}{ }^{\circ} \mathrm{C}^{-1}\right)=\frac{1}{2} D_{m, \text { cloud }} \frac{\sigma v_{h}}{T_{0}-T_{\mathrm{sfc}}},
$$

with mean cloud droplet diameter $D_{m \text {,cloud }}$ and a multiplicative factor $\sigma$ reducing the impact velocity of cloud droplets onto hailstones to account for averaging over all collision angles, following Rasmussen and Heymsfield (1985). We set $\sigma=0.65$ (see Fig. 2 in Rasmussen and 
Heymsfield 1985). Note that the Heymsfield and Pflaum (1985) parameterization, though used in calculations of hailstone density (e.g., ASZ16) was developed initially for graupel. As such, its use for hailstones is an extrapolation. Unlike previous implementations of this parameterization, we ensure that the maximum allowable hailstone density is that of solid ice and the minimum allowable density is set to $\rho_{\min }=500 \mathrm{~kg} \mathrm{~m}^{-3}$, a reasonable minimum expected for hail [e.g., based on data shown in Heymsfield et al. (2018)].

\section{c. Collection of ice}

Previous studies have included ice collection for environmental temperatures down to $-5^{\circ} \mathrm{C}$ (e.g., Brimelow et al. 2002), or even $-40^{\circ} \mathrm{C}$ (e.g., Ziegler et al. 1983; ASZ16). Though never explicitly stated in such studies, in the absence of liquid on the hailstone surface during wet growth, the physical mechanism behind ice-ice sticking presumably is the presence of a quasi-liquid layer (QLL) on the hailstone surface. QLLs are known to exist on ice crystal surfaces, at least at temperatures approaching $0^{\circ} \mathrm{C}$ (e.g., Hosler et al. 1957; Kuroda and Lacmann 1982; Ewing 2004; Sazaki et al. 2012; Asakawa et al. 2016). The disorganized structure of water molecules in QLLs allows for more efficient bonding (or sintering) when the QLL comes into contact with another ice or QLL surface for a sufficiently long amount of time (Hosler et al. 1957). As such, QLLs are thought to play an important role in snowflake aggregation (e.g., Lamb and Verlinde 2011); however, the impact on hailstone ice collection is unknown. The QLL is more likely at temperatures approaching the melting point (Kuroda and Lacmann 1982; Ewing 2004; Sazaki et al. 2012), so permitting ice collection down to $-40^{\circ} \mathrm{C}$, in our view, is not justified. Additionally, these prior hail studies consider the ice collection efficiency to be a function only of the ambient temperature $T_{\infty}$, whereas the hailstone's surface temperature $T_{\text {sfc }}$ is more physically relevant.

Here we adopt a conservative approach by only permitting ice collection when the hailstone surface is wet (i.e., only in wet growth). The ice collection efficiency is set to unity when the hailstone is in wet growth, and zero otherwise. Sensitivity tests of this parameterization and those of other studies are presented in the appendix. Finally, self-collection of hailstones (i.e., hailstone "aggregation") is not included, because there is essentially no evidence for this occurring in nature (C. Knight 2018, personal communication), and it is difficult to envision scenarios in clouds where this may happen and/or be an important process.

The mass growth rate owing to collection of ice crystals is given by

$$
\left(\frac{d m}{d t}\right)_{\text {ice_coll }}=\frac{\pi D_{h}^{2}}{4} \omega_{i} E_{\mathrm{ci}} v_{h},
$$

where $\omega_{i}$ is the ice water content of snow and cloud ice, and $E_{\mathrm{ci}}$ is the ice collection efficiency. The small fall speeds $\left(\leq 1 \mathrm{~m} \mathrm{~s}^{-1}\right)$ of snow and pristine ice crystals (e.g., Pruppacher and Klett 1997, and references therein) are ignored relative to the fall speeds of hailstones.

\section{d. Vapor diffusion}

Hailstones may acquire or lose mass owing to vapor diffusion (deposition and sublimation, respectively), although these processes are of secondary importance to the mass gained via accretion of supercooled liquid water. Diffusion of water vapor molecules is driven by the vapor density gradient between that at the hailstone surface $\rho_{v, \text { sfc }}$ and the ambient value $\rho_{v, \infty}$, with the mass rate of change under ventilated conditions given by (e.g., Lamb and Verlinde 2011)

$$
\left(\frac{d m}{d t}\right)_{\text {diff }}=\chi \operatorname{Re}^{1 / 2} \operatorname{Sc}^{1 / 3} \pi D_{h} D_{v}\left(\rho_{v, \infty}-\rho_{v, \mathrm{scc}}\right) .
$$

In Eq. (9), Re is the Reynolds number, defined as $\mathrm{Re}=$ $v_{h} D_{h} / \nu$, with kinematic viscosity of air $\nu$, Sc is the Schmidt number, defined as $\nu / D_{v}$, where $D_{v}$ is the diffusivity of water vapor in air. Though the true vapor density at the hailstone surface is generally unknown, it is typically assumed to be the equilibrium value $\rho_{v \text {,sfc }} \approx$ $\rho_{v \text {,eq }}\left(T_{\text {sfc }}\right)$ (i.e., Maxwellian growth law), which is a function of the hailstone's surface temperature $T_{\mathrm{sfc}}$ through the integrated form of the Clausius-Clapeyron equation (e.g., Pruppacher and Klett 1997; Lamb and Verlinde 2011). The coefficient $\chi$ is defined in the subsection on vapor and thermal energy transfer coefficients below.

\section{e. Thermal energy balance}

As supercooled liquid water freezes on the hailstone surface, the enthalpy of fusion $\ell_{f}$ is released, increasing $T_{\text {sfc }}$ over $T_{\infty}$ at a rate

$$
\left(\frac{d q}{d t}\right)_{\mathrm{frz}}=\ell_{f}\left(\frac{d m}{d t}\right)_{\mathrm{accr}} F_{f} .
$$

In Eq. (10), $F_{f}$ is the fraction of liquid frozen in a given time step, which is equal to unity during dry growth conditions but is $<1$ during wet growth. Similarly, the phase change associated with vapor diffusion leads to heating or cooling of the hailstone surface at a rate given by

$$
\left(\frac{d q}{d t}\right)_{\mathrm{diff}}=\left(\frac{d m}{d t}\right)_{\mathrm{diff}} \ell_{s}
$$


where $\ell_{s}$ is the enthalpy of sublimation. If the hailstone surface is liquid, $\ell_{s}$ is replaced by $\ell_{v}$, the enthalpy of vaporization, in Eq. (11). The sign convention adopted in this study is as follows. When $d q / d t>0$, thermal energy flow is directed into the hailstone, heating the hailstone's surface (e.g., via freezing of supercooled liquid water or mass growth by vapor deposition), and $d q / d t<0$ indicates cooling the hailstone's surface (e.g., via mass loss owing to sublimation). Note that situations may arise in which the hailstone is growing via accretion of supercooled liquid drops and simultaneously losing mass via sublimation.

The temperature gradient arising from net heating or cooling of the hailstone surface leads to thermal energy transfer away from or toward the hailstone via ventilated conduction, which can be written following Macklin (1963), Macklin and Bailey (1966), Bailey and Macklin (1968), and Rasmussen and Heymsfield (1987a) as

$$
\left(\frac{d q}{d t}\right)_{\text {conduction }}=-\chi \operatorname{Re}^{1 / 2} \operatorname{Pr}^{1 / 3} \pi D_{h} k_{T}\left(T_{\text {sfc }}-T_{\infty}\right),
$$

where $\chi$ is a transfer coefficient (more on this below), $\operatorname{Pr}$ is the Prandtl number, defined as $\operatorname{Pr}=\nu / K_{a}$, with thermal diffusivity of air $K_{a}$, and $k_{T}$ is the thermal conductivity of air. The negative sign ensures that thermal energy is directed away from the hailstone $(d q / d t<0)$ if $T_{\text {sfc }}>T_{\infty}$.

Owing to the processes described above, in general $T_{\text {sfc }} \neq T_{\infty}$. Thus, there is an additional exchange of thermal energy when supercooled liquid and ice crystals (which are assumed to be at the ambient temperature $\left.T_{\infty}\right)$ are collected, given by

$$
\left(\frac{d q}{d t}\right)_{\text {ice }}=-c_{i}\left(T_{\text {sfc }}-T_{\infty}\right)\left(\frac{d m}{d t}\right)_{\text {ice_coll }}
$$

for collected ice, and

$$
\left(\frac{d q}{d t}\right)_{\text {liq }}=-c_{w}\left(T_{\text {sfc }}-T_{\infty}\right)\left(\frac{d m}{d t}\right)_{\text {accr }}
$$

for collected liquid. In these expressions, $c_{i}$ and $c_{w}$ are the specific heat capacities of ice and liquid, respectively. The negative signs ensure that thermal energy is removed from the hailstone to warm the accreted liquid or collected ice when $T_{\text {sfc }}>T_{\infty}$.

Therefore, the overall thermal energy balance equation can be written as

$$
\begin{gathered}
\left(\frac{d q}{d t}\right)_{\mathrm{frz}}+\left(\frac{d q}{d t}\right)_{\mathrm{diff}}+\left(\frac{d q}{d t}\right)_{\text {conduction }} \\
+\left(\frac{d q}{d t}\right)_{\mathrm{liq}}+\left(\frac{d q}{d t}\right)_{\mathrm{ice}}=0 .
\end{gathered}
$$

Substituting the microphysical and thermodynamic expressions from above, we can solve for the hailstone surface temperature $T_{\text {sfc }}$ :

$$
T_{\text {sfc }}=\frac{\ell_{f} \dot{m}_{\text {accr }} F_{f}+\ell_{s} \dot{m}_{\text {diff }}+\left(\dot{m}_{\text {accr }} c_{w}+\dot{m}_{\text {ice_coll }} c_{i}+\chi \operatorname{Re}^{1 / 2} \operatorname{Pr}^{1 / 3} k_{t} \pi D_{h}\right) T_{\infty}}{\dot{m}_{\text {accr }} c_{w}+\dot{m}_{\text {ice_coll }} c_{i}+\chi \operatorname{Re}^{1 / 2} \operatorname{Pr}^{1 / 3} k_{t} \pi D_{h}},
$$

where for clarity we have used the dot notation $\dot{m}$ to indicate the time derivative. Following Nelson (1983), this expression is initially solved assuming $F_{f}=1$. Note that, because we assume the vapor density at the hailstone surface is the equilibrium value [i.e., $\rho_{v, \mathrm{sfc}} \approx$ $\left.\rho_{v, \text { eq }}\left(T_{\text {sfc }}\right)\right]$ in the diffusion term $\dot{m}_{\text {diff }}$, Eq. (16) must be solved numerically. We do so by iteration, minimizing the difference between the left and right sides of Eq. (16), with a $T_{\text {sfc }}$ increment of $0.05 \mathrm{~K}$. If the resulting $T_{\text {sfc }}<T_{0}$, the hailstone remains in the dry growth regime. If the resulting $T_{\mathrm{sfc}} \geq T_{0}$, the hailstone has transitioned to the wet growth regime: here, $T_{\text {sfc }}$ is set to $T_{0}$ and the wet growth module (described next) is applied on subsequent time steps.

\section{f. Wet growth}

When the hailstone collects so much supercooled liquid that the increase in its surface temperature cannot be adequately offset by conduction, $T_{\mathrm{sfc}}$ may rise until it reaches $0^{\circ} \mathrm{C}$. At this point, liquid may persist on the hailstone surface in what is known as the wet growth regime. In such cases, there are several important changes to the hail growth trajectory model: $T_{\mathrm{sfc}}$ is set to $T_{0}=273.15 \mathrm{~K}$, the enthalpy of sublimation is replaced with the enthalpy of vaporization $\left(\ell_{s} \rightarrow \ell_{v}\right)$, the vapor density at the hailstone surface is set to its value at $T_{0}\left[\rho_{v \text {,sfc }} \approx \rho_{v \text {,eq }}\left(T_{0}\right)\right]$, and the fraction of total accreted liquid that freezes $F_{f}<1$. After these substitutions, following Nelson (1983), we solve Eq. (16) for $F_{f}$ :

$$
F_{f}=\frac{-\ell_{v} \dot{m}_{\mathrm{diff}}+\left(\chi \operatorname{Re}^{1 / 2} \operatorname{Pr}^{1 / 3} k_{t} \pi D_{h}+\dot{m}_{\mathrm{accr}} c_{w}+\dot{m}_{\mathrm{ice} \_ \text {coll }} c_{i}\right)\left(T_{0}-T_{\infty}\right)}{\ell_{f} \dot{m}_{\mathrm{accr}}}
$$


to determine the fraction of collected water that freezes.

\section{g. Soaking and shedding of unfrozen liquid}

Because only a fraction of the collected liquid water freezes during wet growth, we employ an adaptation of the spongy growth parameterization of Rasmussen and Heymsfield (1987a) for the density of this added ice:

$$
\rho_{h}^{\prime}=\left(1-0.08 F_{f}\right) F_{f} \times 10^{3},
$$

where the factor of $10^{3}$ is to ensure units of $\mathrm{kg} \mathrm{m}^{-3}$. Note that, as $F_{f}$ decreases toward zero, the density of the added ice similarly decreases. The physical interpretation of low-density deposits is that only a small fraction of the liquid freezes as dendritic crystals within the liquid, creating an ice mesh or matrix that acts as a "sponge," retaining the liquid (e.g., Lesins and List 1986; Rasmussen and Heymsfield 1987a). The remaining fraction $1-F_{f}$ is unfrozen liquid and has two possible fates. First, if the average hailstone density is less than that of solid ice, some of this liquid may soak into the particle, filling interior air pockets ${ }^{2}$ and increasing the hailstone's density. The mass of liquid needed to fully soak the hailstone and bring its density to that of solid ice is computed. If the amount of unfrozen liquid on the hailstone exceeds this value, the hailstone soaks and the remainder of unfrozen liquid collects on the hailstone's surface. If the amount of unfrozen liquid is less than that needed to soak, all of this unfrozen liquid is soaked and the hailstone density increases accordingly. A similar densification from soaking was allowed in Ziegler et al. (1983) and Rasmussen and Heymsfield (1987a), and subsequently incorporated into the HAILCAST model (ASZ16). None of these studies describe the fate of the soaked liquid; here, the liquid soaked into the hailstone interior remains there, contributing to the total hailstone mass and thus increasing its density. However, it does not participate in the thermal energy balance.

Any additional liquid water that does not soak into the hailstone interior is allowed to collect on the surface until a critical threshold $m_{w, \text { crit }}$ is met (Rasmussen and Heymsfield 1987a):

$$
m_{w, \text { crit }}=2.68 \times 10^{-4} \mathrm{~kg}+0.1390\left(m_{\text {ice }}+m_{\text {soaked }}\right),
$$

\footnotetext{
${ }^{2}$ This treatment is a simplification: in general, liquid on the surface may not be able to migrate into the interior of the hailstone. Thus, our parameterization could lead to an overestimate of hailstone density. However, in the absence of detailed information about the hailstone's shape and distribution of mass within the hailstone, this is the most straightforward way to account for the densification from soaking.
}

where $m_{\text {ice }}$ and $m_{\text {soaked }}$ are the masses of ice and soaked liquid water in the hailstone. Above this threshold, all excess liquid water is shed (Rasmussen and Heymsfield 1987a). Note that some previous studies implicitly assume that all unfrozen liquid is immediately shed (e.g., Nelson 1983), limiting the mass that can be incorporated into the growing hailstone. In contrast, here, the not-yetfrozen liquid retained on the surface after shedding and soaking ( $\left.m_{\text {retained }} \leq m_{w, \text { crit }}\right)$ is accounted for in the thermal energy balance equations, and thus is accounted for in the subsequent $F_{f}$ calculations at each time step $\Delta t$ by making the denominator of Eq. (17):

$$
\ell_{f}\left(\dot{m}_{\mathrm{accr}}+\frac{m_{\text {retained }}}{\Delta t}\right)
$$

where $\dot{m}_{\text {accr }}$ represents the growth rate from newly collected mass, and $m_{\text {retained }}$ is the liquid mass retained from the previous time step. Given the lack of detailed information about whether or how liquid preferentially freezes within or on the hailstone, the same $F_{f}$ is assumed for all liquid on the surface that collected in a given time step, and the portion retained on the surface from previous time steps. This liquid mass retained on the surface is carried on the hailstone until all of it is frozen or shed.

\section{h. Thermal energy and mass transfer coefficients}

The thermal energy and mass transfer coefficients account for the effects of ventilation and follow Rasmussen and Heymsfield (1987a), Ryzhkov et al. (2013a), and ASZ16, written here in the formalism of Macklin (1963) for consistency among the different Reynolds number regimes. For $\mathrm{Re}<6000$, the ventilation coefficients from Pruppacher and Rasmussen (1979) are used,

$$
\chi=\frac{2}{\operatorname{Re}^{1 / 2} \operatorname{Pr}^{1 / 3}}\left(0.78+0.308 \operatorname{Pr}^{1 / 3} \operatorname{Re}^{1 / 2}\right)
$$

for thermal energy transfer, and

$$
\chi=\frac{2}{\operatorname{Re}^{1 / 2} \operatorname{Sc}^{1 / 3}}\left(0.78+0.308 \mathrm{Sc}^{1 / 3} \operatorname{Re}^{1 / 2}\right)
$$

for mass transfer. For $6000 \leq \operatorname{Re}<2 \times 10^{4}$, Macklin (1963) found

$$
\chi \approx 0.76
$$

This value applies to spheres, which we assume here, but generally depends on axis ratio. ${ }^{3}$ For $\mathrm{Re} \geq 2 \times 10^{4}$,

\footnotetext{
${ }^{3}$ For example, Macklin (1963) found that $\chi$ increased from 0.76 for spheres (axis ratio of unity) to 0.89 for oblate spheroids with axis ratio of 0.5 .
} 


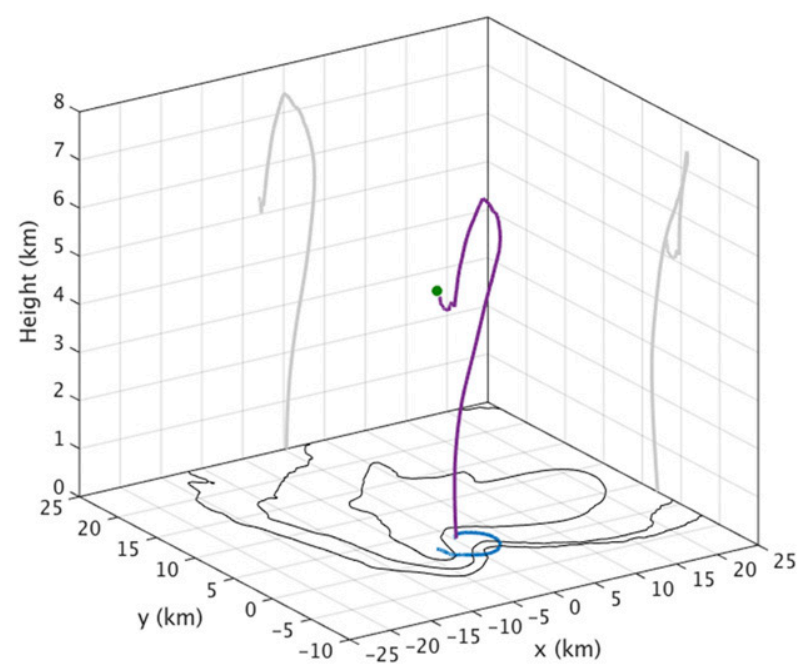

FIG. 1. Example 3D trajectory for a hailstone initialized with a 5-mm-diameter embryo for the umax31 supercell storm. The 2D projections of the trajectory are shown in gray on the lateral walls and blue on the bottom. The simulated reflectivity factor (at the lowest model level) contours of 10,30 , and $50 \mathrm{~dB} z$ are shown on the bottom in black. The green circle represents the embryo's initial location.

Rasmussen and Heymsfield (1987a) used the following relation, derived from laboratory measurements of rough artificial hailstones obtained by Bailey and Macklin (1968):

$$
\chi=0.57+9.0 \times 10^{-6} \mathrm{Re},
$$

which accounts for the increasing energy and mass transfer for increasingly large hailstones.

\section{i. Update to hailstone size}

After the microphysical calculations are performed, the change in hailstone mass $\Delta m$ in a time step and the density of the growth layer $\rho_{h}^{\prime}$ are used, along with an assumption of spherical geometry, to calculate the new hailstone diameter:

$$
D_{h, \text { new }}=\left(D_{h, \text { old }}^{3}+\frac{6 \Delta m}{\rho_{h}^{\prime} \pi}\right)^{1 / 3} .
$$

This updated diameter and the computed average hailstone density (i.e., total mass divided by total volume) are used to update the hailstone fall speed following Eq. (1).

\section{Idealized tests}

\section{a. Single trajectory example}

First, we show the results of a single hailstone growth trajectory through a simulated supercell storm. We use
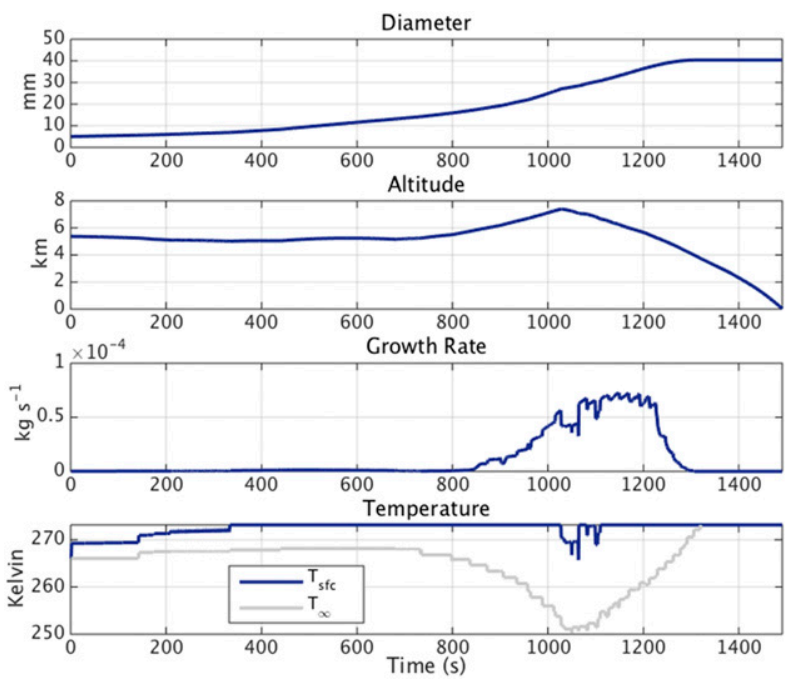

FIG. 2. Time series for the trajectory shown in Fig. 1: (top to bottom) diameter ( $\mathrm{mm}$ ), hailstone's altitude ( $\mathrm{km} \mathrm{AGL),} \mathrm{instanta-}$ neous growth rate $\left(\mathrm{kg} \mathrm{s}^{-1}\right)$, and hailstone surface temperature $T_{\text {sfc }}$ (blue) and the ambient temperature $T_{\infty}$ (gray).

the "umax31" or "test supercell case" from DK17, which is the standard CM1 "quarter circle hodograph" supercell simulation, with horizontal grid spacings of $500 \mathrm{~m}$ and vertical grid spacing of $250 \mathrm{~m}$. See DK17 for additional simulation details. The hailstone trajectory shown in three dimensions (Fig. 1) reveals several features that exemplify hail trajectories in supercell storms. First, the 2D projection of the hailstone (blue line on the bottom boundary of the domain shown) traces out a cyclonically curved path across the main updraft, consistent with earlier findings described in the introduction. Second, the hailstone only ascends $\sim 2.5 \mathrm{~km}$ before falling out of the storm; in other words, large or repeated up/down vertical excursions are not observed in these trajectory calculations. Third, the final fallout of the hailstone is on the left (relative to storm motion) side of the low-level mesocyclone, a typical place where large hail is observed in supercells (e.g., Browning 1964; Browning and Foote 1976; Kumjian and Ryzhkov 2008).

A time series of relevant quantities for this trajectory (Fig. 2) shows steady growth of the hailstone, from an initial embryo at $0.5 \mathrm{~cm}$ in diameter to a diameter of $>4 \mathrm{~cm}$. Prior to $800 \mathrm{~s}$, small growth rates $(<1.3 \times$ $10^{-6} \mathrm{~kg} \mathrm{~s}^{-1}$ ) occur in a relatively flat trajectory between about 5 and $6 \mathrm{~km} \mathrm{AGL}$. More significant growth rates $>5 \times 10^{-5} \mathrm{~kg} \mathrm{~s}^{-1}$ occur as the hailstone then ascends in the updraft to about $7.5 \mathrm{~km}$ AGL, and then descends. Thus, growth occurs during both the ascent and descent for this particular hailstone. During the 5$6 \mathrm{~min}$ of more significant growth rates, the hailstone doubles in size from 2 to $4 \mathrm{~cm}$. 


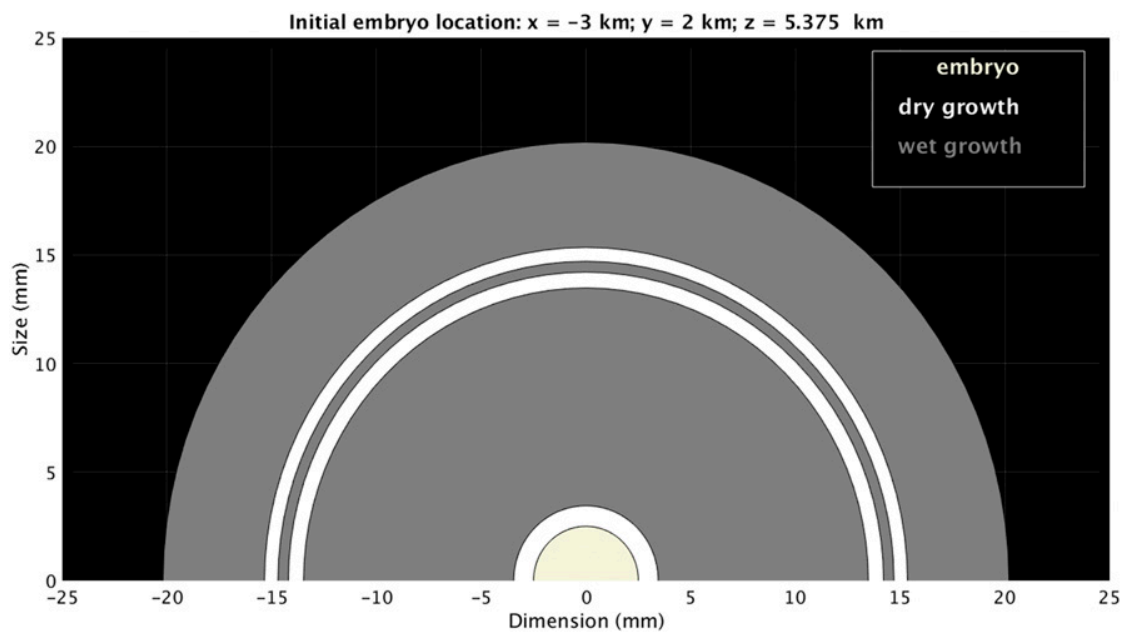

FIG. 3. Simulated growth layers for the hailstone trajectory shown in Figs. 1 and 2, which has an initial embryo location indicated above the panel. The dark gray layers represent wet growth, and the white layers represent dry growth. The embryo is colored in a beige. Spherical symmetry is assumed in the trajectory calculations, though only half the hailstone is shown here.

A time series of ambient temperature $T_{\infty}$ and hailstone surface temperature $T_{\text {sfc }}$ (Fig. 2) reveals that for much of this trajectory, the hailstone is undergoing wet growth. In real hailstones, differing growth regimes lead to the layered appearance: milky or opaque ice indicates dry growth, whereas translucent or clear ice indicates wet growth. Based on the wet and dry growth periods for this example hailstone trajectory, we depict the growth layers in Fig. 3. This example clearly shows that alternating growth regimes are possible without repeated up/down recycling trajectories; further, the dry/wet growth regimes may occur at very similar altitudes simply by advecting the hailstone into different regions of the updraft characterized by different supercooled liquid water contents and/or temperatures. Interestingly, the last $\sim 1 \mathrm{~cm}$ of thickness is acquired in a wet-growth regime as the hailstone descended through the updraft at ambient temperatures greater than about $-15^{\circ} \mathrm{C}$, as suggested by Knight and Knight (2005) for very large hailstones observed in the 2003 Aurora, Nebraska storm. Thus, growth trajectory details and the resulting hailstone are consistent with findings from previous hailstone trajectory studies.

\section{b. Ensembles of trajectories}

Next, we initialize a large number of trajectories through two different storm simulations: an idealized squall line and a supercell storm. The idea is to employ a sanity check: squall lines typically do not produce very large hail, whereas supercell storms are known to produce giant hail (e.g., Blair et al. 2011, 2017). Therefore, we want to see if the trajectory model applied naively to CM1 output fields from different simulated storm modes will produce differences in the resulting hail sizes, and how these compare to expectations. For both, the trajectories are run through a single output time (implicitly assuming steady-state storm

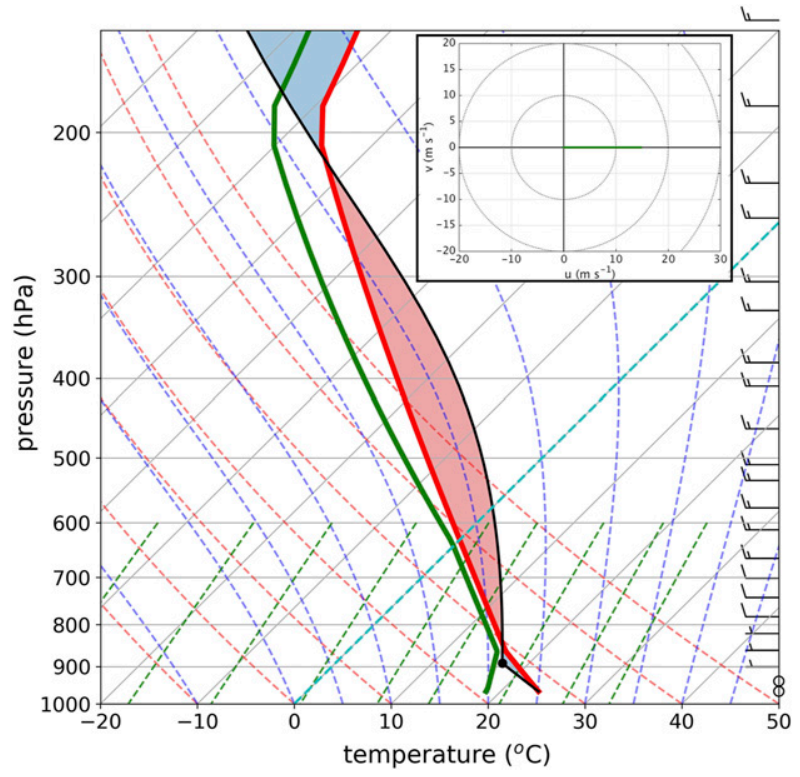

FIG. 4. Initial sounding for the squall-line simulation. Red and green lines indicate the temperature and dewpoint temperature, respectively. The black line is the surface-based parcel; salmon shading is CAPE, and light blue shading is CIN. Ground-relative wind barbs are in $\mathrm{m} \mathrm{s}^{-1}$ (half barb $=5 \mathrm{~m} \mathrm{~s}^{-1}$, full barb $=10 \mathrm{~m} \mathrm{~s}^{-1}$ ). The ground-relative hodograph is shown inset in the upper right. 

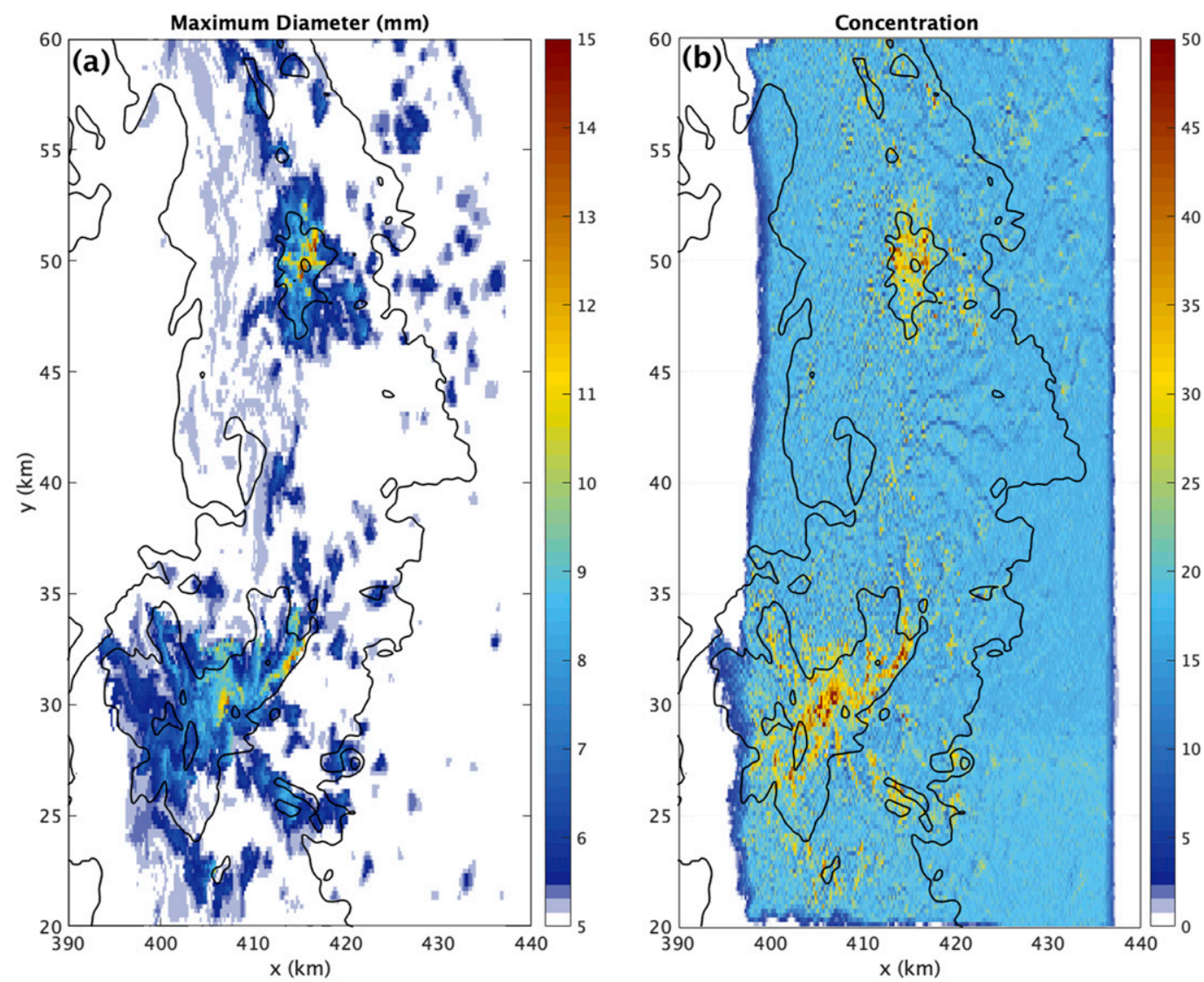

FIG. 5. Results of hailstone growth trajectory calculations driven by a simulated squall line. (a) Maximum (unmelted) diameter of hailstones at the surface in each grid box, shaded according to the scale. (b) Concentration of particles reaching the surface at a given grid box, shaded according to scale. In both panels, the 40-, 50-, and 60-dB $z$ contours of simulated reflectivity factor at the lowest model level are overlaid (black lines). The embryos were seeded at every grid box from $x=400$ to $440 \mathrm{~km}, y=20$ to $60 \mathrm{~km}$, and $z=3.3$ to $9.6 \mathrm{~km}$. The initial embryo diameter was $5 \mathrm{~mm}$, with an initial density of $917 \mathrm{~kg} \mathrm{~m}^{-3}$. Maximum hailstone diameter is $<15 \mathrm{~mm}$.

conditions) during the mature phase of the storms' life cycle, as in Grant and van den Heever (2014) and DK17, and all other previous hail growth trajectory studies. Note that the steady state assumption used here is less valid for squall-line updrafts. Additional tests will be performed in the following subsections and in the appendix.

\section{1) SQuall LiNe}

The first idealized storm test uses a simulated squall line. The storm is simulated using CM1, with a $1000 \mathrm{~km} \times 60 \mathrm{~km} \times 20 \mathrm{~km}$ domain, with 200 -m horizontal grid spacing and vertical grid spacing is $50 \mathrm{~m}$ in the lowest $3 \mathrm{~km}$, is stretched from 50 to $1000 \mathrm{~m}$ at the model top (21.375 km AGL). The simulation employs a time step of $0.75 \mathrm{~s}$, no surface fluxes or PBL scheme, and a free-slip lower boundary condition. The analytic sounding represents an environment characteristic of squall lines in mid-Atlantic regions or coastal regions (e.g., Letkewicz and Parker 2010; Lombardo and Colle
2012; Lombardo and Kading 2018), including a rather moist troposphere, with about $1500 \mathrm{~J} \mathrm{~kg}^{-1}$ of surfacebased CAPE and $15 \mathrm{~m} \mathrm{~s}^{-1}$ of wind shear in the lowest $3.5 \mathrm{~km}$ (Fig. 4). The storm is initiated using momentum forcing (Morrison et al. 2015) with random 2-K thermal perturbations to promote 3D circulations. Other details may be found in K. Lombardo (2020, manuscript submitted to J. Atmos. Sci.).

Solid-ice embryos of $0.5-\mathrm{cm}$ initial diameter were seeded at every grid box across a segment of the mature squall (5.5 h into the simulation) line extending from $x=$ 400 to $440 \mathrm{~km}, y=20$ to $60 \mathrm{~km}$, and $z=3.3$ to $9.6 \mathrm{~km}$, for a total of 727218 embryos (i.e., one per grid box). This region encompasses the main convective line, including some convective cells with simulated reflectivity factor $Z_{H}>50 \mathrm{~dB} z$ (see Fig. 5). Growth trajectory calculations were performed for each embryo initialized. Figure 5a shows the final maximum (unmelted) hailstone size in each grid box at the lowest model level and 
Fig. 5b displays the concentration of particles ending up in each grid box at the lowest model level. The maximum hailstone size attained is $<1.5 \mathrm{~cm}$; such small hail likely would entirely melt on its descent through the midlatitude squall-line environment (e.g., Rasmussen and Heymsfield 1987a; Ryzhkov et al. 2013a,b). Notably, the largest final sizes and greatest concentrations generally are confined to areas of the largest simulated $Z_{H}$, demonstrating consistency with the model-simulated precipitation fields. The largest particles produced by the trajectory calculations also fell in the few regions at the lowest model grid level that contained nonnegligible hail mass mixing ratio as simulated by CM1 (not shown). These larger particles followed simple up/down trajectories during growth, as expected from the generally $2 \mathrm{D}$ airflow in squall lines in this type of environment with unidirectional shear (e.g., Thorpe et al. 1982; Carbone 1982; Rotunno et al. 1988; Markowski and Richardson 2010). Thus, as anticipated based on experience, hailstone growth trajectory calculations applied to a squall-line simulation results in no severe-sized hail, but numerous smaller stones that very likely would melt entirely into large raindrops on their descent. This is despite the squall line having maximum updraft speeds greater than $25 \mathrm{~m} \mathrm{~s}^{-1}$ (not shown).

\section{2) SuPERCELL}

For the next idealized test, we perform the same type of hailstone growth trajectory calculations, this time driven by an idealized simulation of a tornadic supercell [i.e., a simulation of the well-documented, significantly tornadic storm that occurred on 24 May 2011, in El Reno, Oklahoma; see French et al. (2013, 2015) and Orf et al. (2017) for details]. We again use $\mathrm{CM} 1$, in a $120 \mathrm{~km} \times 120 \mathrm{~km} \times 20 \mathrm{~km}$ domain with $500-\mathrm{m}$ horizontal grid spacing and a uniform $250-\mathrm{m}$ vertical grid spacing, with a 1-s time step. The simulation has no Coriolis, no PBL scheme, and a free-slip lower boundary. Other settings are as the standard CM1 supercell simulation, similar to DK17 (among many others). The horizontally homogeneous base-state environment contains $4211 \mathrm{~J} \mathrm{~kg}^{-1}$ of surface-based CAPE, $25.3 \mathrm{~m} \mathrm{~s}^{-1}$ of $0-6-\mathrm{km}$ wind shear, and has a large, clockwise turning hodograph with $508 \mathrm{~m}^{2} \mathrm{~s}^{-2}$ of $0-3-\mathrm{km}$ storm-relative helicity (Fig. 6). Such a highly unstable, sheared environment is favorable for strong supercells, and the simulated storm has updrafts exceeding $60 \mathrm{~m} \mathrm{~s}^{-1}$ at $5 \mathrm{~km}$ AGL.

We expect the supercell to produce severe hail, based on what was actually reported (up to $7.5 \mathrm{~cm}$, according to Storm Data), as well as the fact that most U.S. Plains supercells contain hail at least $5 \mathrm{~cm}$ in maximum dimension according to Blair et al. (2017).

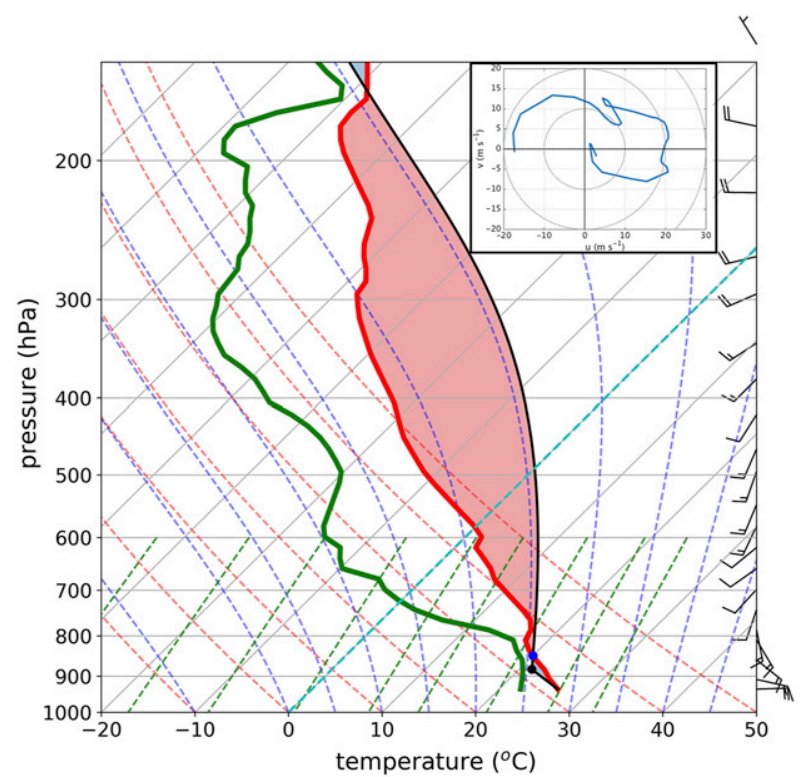

FIG. 6. Initial environmental sounding for the 24 May $2011 \mathrm{El}$ Reno supercell simulation, as in Fig. 4. Storm-relative winds and 0-15-km AGL storm-relative hodograph are shown.

As before, solid-ice embryos of 0.5 -cm initial diameter were seeded at every grid box centered roughly on the main updraft of the supercell, from $x=-30.5$ to $4.5 \mathrm{~km}$, $y=-23.0$ to $12.0 \mathrm{~km}$, and $z=2.4$ to $9.9 \mathrm{~km}$. This results in a total of 156271 embryos. Figure 7 shows the maximum size and concentrations found at the lowest model level. 290 seeds reached final diameters $>1.5 \mathrm{~cm}$ (the maximum diameter achieved in the squall-line simulation), with 23 exceeding the "severe" size threshold $(>2.54 \mathrm{~cm}$ in diameter). This time, the maximum hailstone size attained is $6.34 \mathrm{~cm}$, which, following U.S. National Weather Service convention, registers as significantly severe. Owing to its large size and fall speed, this hailstone would melt very little $(<10 \%$ change in diameter) on its descent to the surface in most supercell environments (e.g., Ryzhkov et al. 2013a). Additionally, the largest stones fell along the inner edge of the inflow notch and hook echo, strikingly consistent to locations of large hail typically found in supercells (e.g., Browning and Foote 1976; Kumjian and Ryzhkov 2008; Witt et al. 2018), to the north, northwest, and west of the low-level mesocyclone. These regions also exhibited the largest concentrations of particles. Trajectories of the larger stones exhibited similarities to those shown in previous studies and Fig. 1 (not shown).

Given that the hail growth trajectory model setup was identical in each case, the resulting differences in sizes are directly attributable to the different storms into which the embryos were seeded and the resulting trajectories growing hailstones took through the 

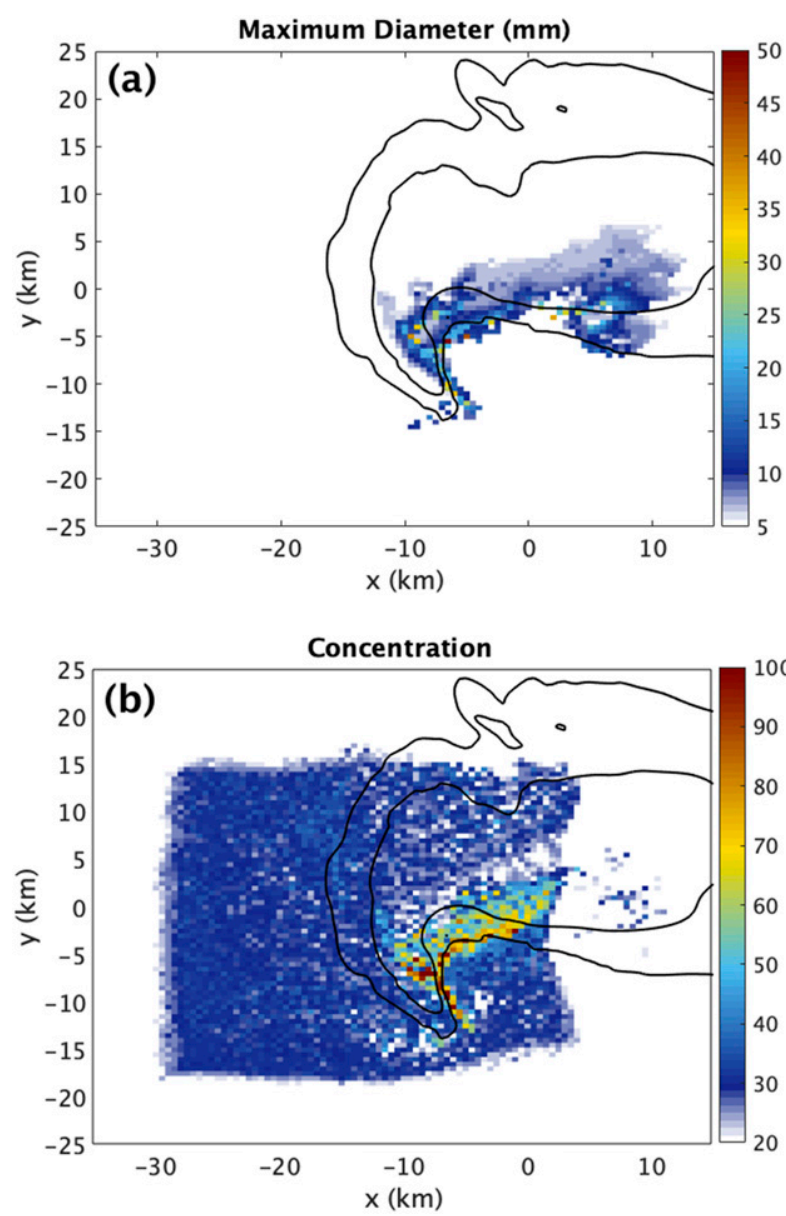

FIG. 7. As in Fig. 5, but for the El Reno supercell storm. Note the extended range of the color scales in both panels. Embryo seeds were placed at $x=-30.5$ to $4.5 \mathrm{~km}, y=-23.0$ to $12.0 \mathrm{~km}$, and $z=$ 2.375 to $9.875 \mathrm{~km}$. All embryos started as solid ice with an initial diameter of $5 \mathrm{~mm}$. Maximum hailstone size is $63.4 \mathrm{~mm}$ in diameter.

storms. The general success in reproducing significantly severe hail for the supercell and subsevere hail for the squall line, including appropriate fallout regions, lends confidence in our trajectory calculations, at least in a qualitative sense.

\section{c. Varying-shear experiments}

DK17 ran a series of supercell simulations with varying vertical wind shear profiles. They found that the hail mass produced increased with increasing deep-layer $(0-6-\mathrm{km})$ shear. The increase in hail production resulted from the updraft being enlarged in the direction of the shear vector, leading to greater updraft volumes capable of hail production. Similarly, Warren et al. (2017) found increases in precipitation mass (including hail) for increases in upper-level (6-12-km) shear. However, both studies used bulk microphysics schemes and subsequently could not determine the impact of varying

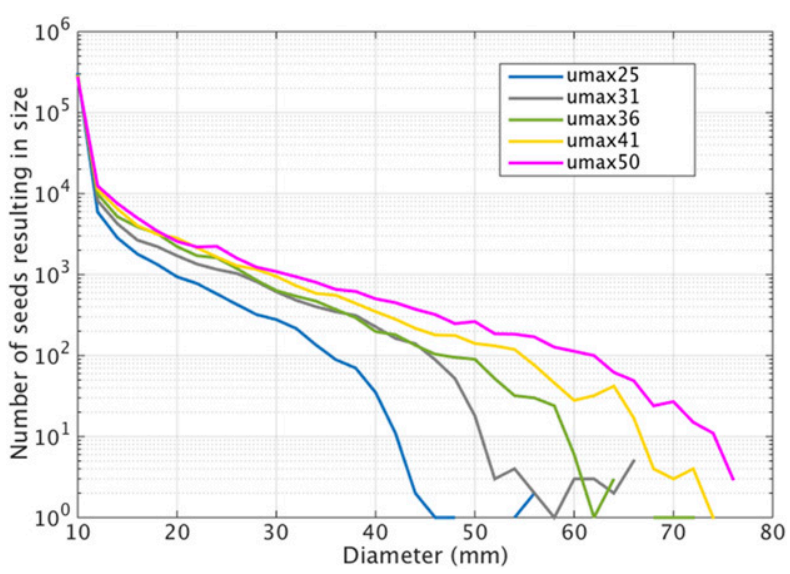

FIG. 8. Distribution of hailstone sizes resulting from initial embryos of 2.5, 5.0,7.5, and $10.0 \mathrm{~mm}$ in diameter, with solid ice density $\left(917 \mathrm{~kg} \mathrm{~m}^{-1}\right)$, seeded at $x=-15.5$ to $9.5 \mathrm{~km}, y=-15.5$ to $9.5 \mathrm{~km}$, and $z=3.375$ to $10.625 \mathrm{~km}$. The different colors correspond to differing amounts of deep-layer wind shear, following the naming and color conventions of DK17.

shear on hail sizes. Here, we run the trajectory growth model with the set of supercell simulation composites from DK17. The simulations umax25, umax31, umax36, umax41, and umax50 (hereafter the "umax" cases) use the idealized quarter-circle hodograph from Weisman and Rotunno (2000), with increasing values of $0-6-\mathrm{km}$ shear, with a fixed thermodynamic profile containing approximately $2200 \mathrm{~J} \mathrm{~kg}^{-1}$ of CAPE (see DK17 for details). For each, as in DK17, we initialize embryos of varying sizes $(0.25,0.50,0.75$, and $1.0 \mathrm{~cm}$ in diameter) at each grid point across a broad volume around the updraft $(25 \mathrm{~km} \times 25 \mathrm{~km} \times 7.5 \mathrm{~km}$ in $x, y$, and $z$, respectively). This leads to 78030 embryos of each size (312120 total), each of which with initial density of $917 \mathrm{~kg} \mathrm{~m}^{-3}$, for each of the 5 supercell simulations.

Figure 8 shows the resulting distribution of final hailstone sizes for each case (only particles with final diameters $>1 \mathrm{~cm}$ are shown). The resulting distributions ${ }^{4}$ reveal an approximately exponential decrease with increasing size until the large-size tail, which drops off more rapidly. The results indicate that, generally, increasing 0-6-km (deep-layer) vertical wind shear results in increased hail sizes and concentrations of hailstones of a given size. In particular, a clear, monotonic shift in the large-size end of the distribution is visible for increasing deep-layer zonal shear (i.e., going from umax 25 , umax31, etc.). This shift toward larger sizes

\footnotetext{
${ }^{4}$ These distributions are not the traditional hail size distribution (defined as the number of hailstones of a particular size per unit volume), but rather the total distribution of sizes across the entire storm resulting from all initialized embryos.
} 

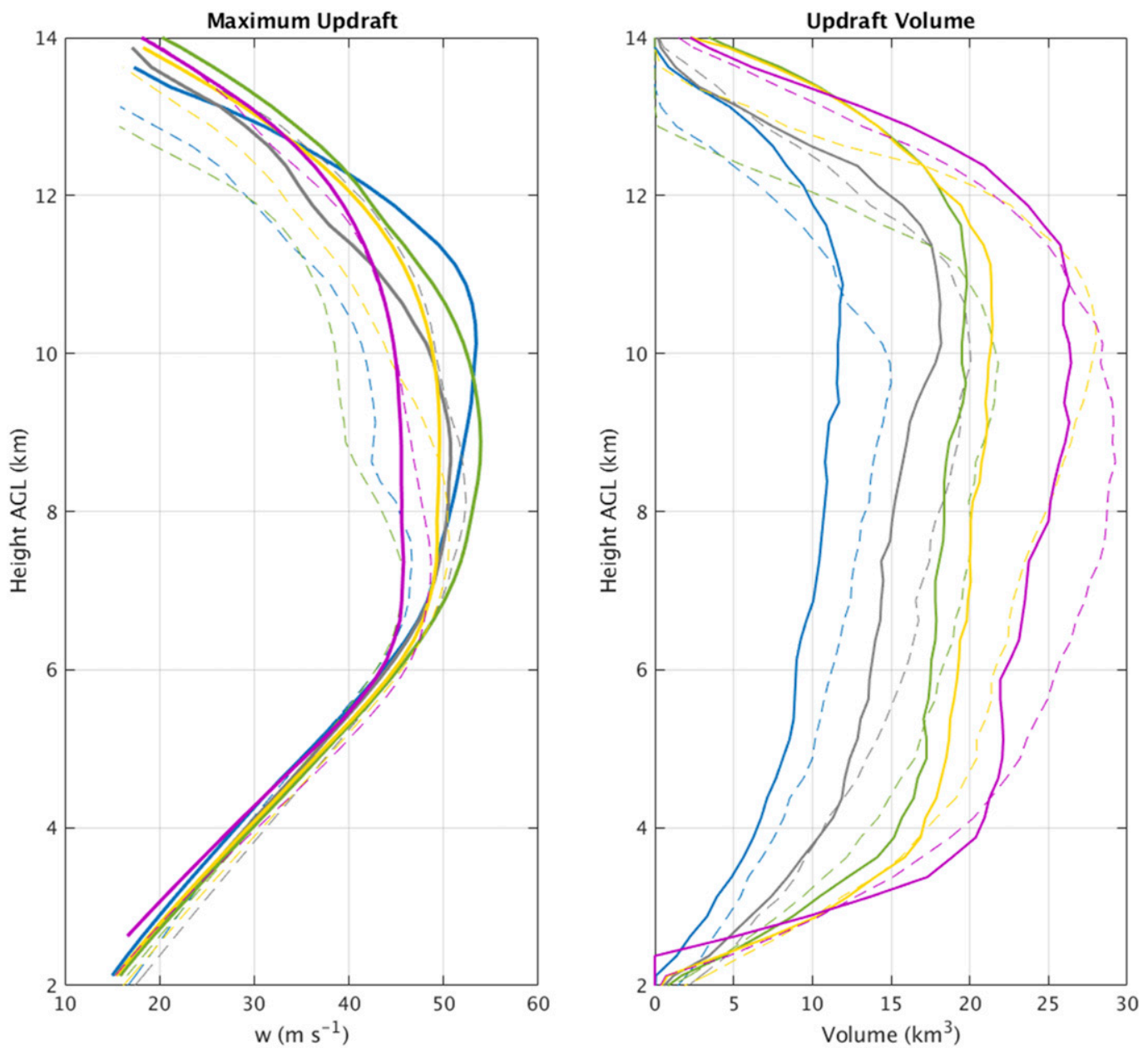

FIG. 9. (left) Maximum $w$ profiles for each simulation, color coded as in previous figures and DK17. Solid lines indicate umax cases (with weak meridional low-level shear; $\operatorname{vmax}=7 \mathrm{~m} \mathrm{~s}^{-1}$ ), and dashed lines indicate vmax cases (with enhanced meridional low-level shear; vmax $=16 \mathrm{~m} \mathrm{~s}^{-1}$ ). (right) Volume of updraft with $w \geq 15 \mathrm{~m} \mathrm{~s}^{-1}$.

with increased deep-layer shear is confirmed by computing hail size distribution metrics: the median, 90th-percentile, 95th-percentile, and 99th-percentile sizes all increase monotonically with increasing deep-layer shear (not shown). This corroborates the DK17 and Warren et al. (2017) findings of increased hail mass with increased deep-layer vertical wind shear, but builds on those studies by explicitly considering hail sizes using a much more detailed model.

Why does increased deep-layer vertical wind shear lead to increases in hail sizes? Both DK17 and Trapp et al. (2017) found that increasing wind shear leads to increased midlevel updraft area, which may be a response to increased low-level storm-relative wind magnitudes (Warren et al. 2017; Peters et al. 2019). DK17 argue that, given the updraft is where hail formation and growth occurs, a larger volume of this region leads to greater production. We can assess this conclusion with greater detail using the present trajectory model. Figure 9a reveals that, below $\sim 7 \mathrm{~km}$ AGL, the maximum updrafts (as well as 95th-percentile and mean updrafts, not shown) are nearly unchanged across the storm simulations. However, below $\sim 10 \mathrm{~km}$ AGL, increased deep-layer shear indeed leads to increased updraft volume (defined as the volume with $w \geq 15 \mathrm{~m} \mathrm{~s}^{-1}$; similar results for using thresholds of $w \geq 10$ and $w \geq$ $20 \mathrm{~m} \mathrm{~s}^{-3}$ ). Figure 10 shows the joint histogram between hailstone residence time in the updraft $\geq 15 \mathrm{~m} \mathrm{~s}^{-1}$ and final diameter attained. (These results are consistent when using the different updraft speed thresholds). There is a positive correlation between residence time and size, as one would expect. Further, there is an increase in the numbers of trajectories with large residence times with increasing shear. In other words, increased shear leads to larger updrafts, which allows longer hailstone trajectories through the updraft and 

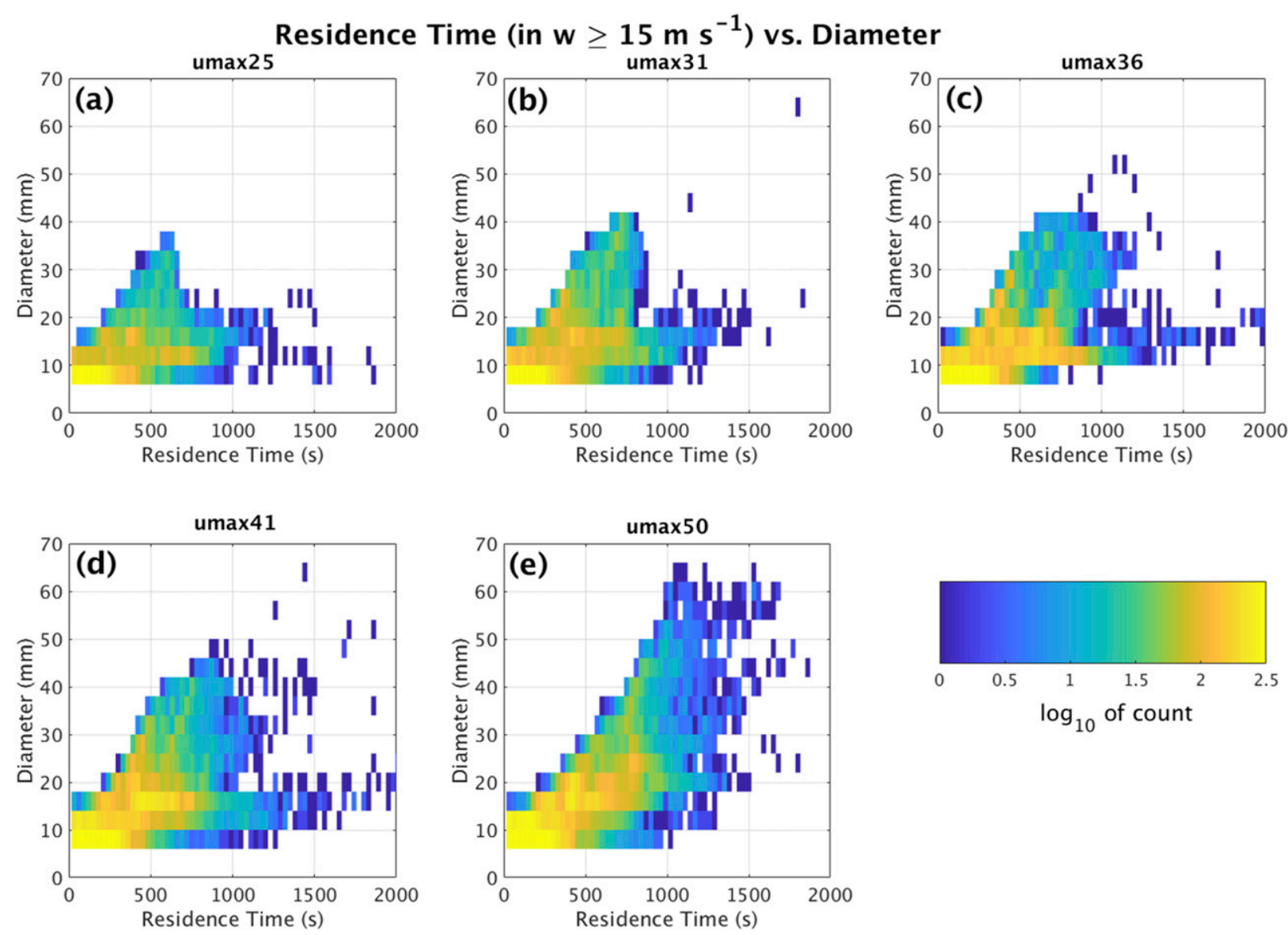

FIG. 10. Joint histograms of residence time within updrafts $\geq 15 \mathrm{~m} \mathrm{~s}^{-1}$ vs the diameter attained for all embryos seeded for each simulation. The shading is the base-10 logarithm of count. Only 5-mm embryos are considered for this plot.

thus more time spent in growth conditions. Interestingly, there seems to be an upper limit to the growth rate as a function of residence time across this set of simulations: for example, hailstones reaching maximum dimensions $>3 \mathrm{~cm}$ require residence times in $\geq 15 \mathrm{~m} \mathrm{~s}^{-1}$ updrafts longer than $400 \mathrm{~s}$. That the trajectories typically last $<2000 \mathrm{~s}$ is in close agreement with previous studies' suggestions of maximum trajectory durations of $<30$ min (e.g., Chalon et al. 1976; Ziegler et al. 1983; Nelson 1983; Heymsfield 1983; Foote 1984) and with the 2000-s cap on trajectory duration in the operational HAILCAST model (ASZ16).

DK17 also found that increasing the 0-2-km "meridional" shear $^{5}$ (the "vmax" cases in their parlance) unexpectedly

\footnotetext{
${ }^{5}$ The meridional component of the shear was confined to low levels based on the observed parameter space of supercell environments, in which the zonal winds tend to increase over a deep layer, whereas most changes to the meridional winds are found at the lowest levels (e.g., Weisman and Rotunno 2000; Markowski and Richardson 2010).
}

decreased hail mass, despite increasing updraft volumes for these cases, as well. Here, we extend their results and find that the vmax cases have smaller hail sizes, and somewhat higher concentrations of smaller stones (Fig. 11, dashed lines). As in the umax cases, updraft speeds are not significantly different below $7 \mathrm{~km}$ AGL (above $7 \mathrm{~km}$, the vmax16 cases have somewhat weaker mean and max updrafts; Fig. 9a). Increasing vmax for a given umax also increases updraft volume (Fig. 9b). Why, then, the smaller hail sizes for vmax cases?

The answer lies in the distribution of trajectory residence times: specifically, vmax cases display a larger number of short residence times, and smaller numbers of longer residence times (Fig. 12). But if the updraft is wider, how is the residence time smaller? Updraft magnitudes in the hail growth zone are not substantially different among the cases (Fig. 9a). Rather, the hailstones could be advected across the updraft faster. Because hailstones take cyclonically curved paths through the updraft, it makes sense to look at storm-relative 



FIG. 11. Hail diameter distribution for umax (solid) and vmax cases (dashed). All embryo sizes considered.

westerly and southerly flow components (i.e., $u>0$ and $v>0$ ) within the updraft and hail growth zone. Figure 13 shows the mean profiles of these flow components conditionally averaged within the updraft $\left(\geq 15 \mathrm{~m} \mathrm{~s}^{-1}\right)$. Increasing deep-layer shear leads to increased average westerly flow within the updraft (Fig. 13a, solid lines); increasing the low-level meridional shear leads to increased $u>0$ by up to $5 \mathrm{~m} \mathrm{~s}^{-1}$ for the umax 25 and umax31 cases, but insignificant differences for the stronger-shear cases within most of the hail growth region, which is $\sim 4$ $9 \mathrm{~km}$ AGL in these simulations (Fig. 13a, dashed lines). In contrast, a considerable shift in $v>0$ magnitudes is evident in the updraft for the vmax cases: $\geq 5 \mathrm{~m} \mathrm{~s}^{-1}$ across all simulations, or $20 \%-100 \%$ relative increases compared to the umax cases (Fig. 13b, compare solid and dashed lines). The magnitude of these changes tends to increase with height through the hail growth region. Thus, greater south-to-north flow within the vmax (increased low-level meridional shear) cases' updrafts advects hailstones across the updraft faster than in the umax (weaker low-level shear) cases, resulting in less residence time and subsequently less growth. Note the differences in residence time are not as pronounced for umax41 (e.g., Fig. 12); consulting Fig. 13, we see that westerly flow is weaker within the updraft at some altitudes in the hail growth region, which may partly counteract the comparatively larger increases in the southerly flow in the vmax16 case.

\section{Discussion and conclusions}

We developed a detailed hailstone growth trajectory model that accounts for microphysical processes important for hail growth. It is driven by numerical model simulations of convective storms, in which hailstone embryos are initialized in and around the simulated storms' updrafts. As such, it may be used to explore how hail growth varies in storms across different environments in order to untangle the environmental controls on hail size. Idealized tests demonstrate features consistent with many previous hailstone trajectory studies, including that hailstone trajectories follow cyclonically curved paths (when projected onto the horizontal plane) through the updraft with only modest vertical excursions 

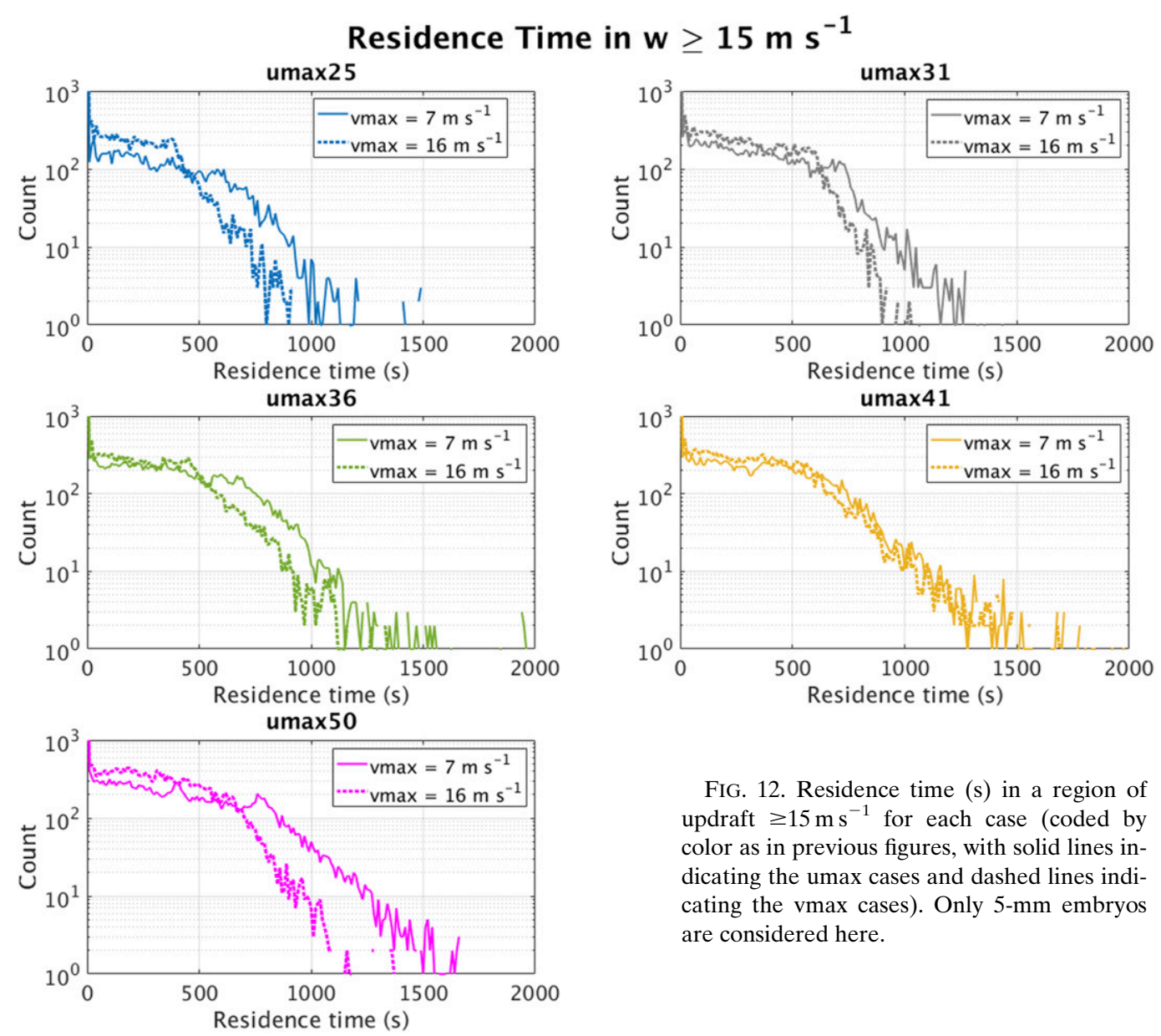

FIG. 12. Residence time (s) in a region of updraft $\geq 15 \mathrm{~m} \mathrm{~s}^{-1}$ for each case (coded by color as in previous figures, with solid lines indicating the umax cases and dashed lines indicating the vmax cases). Only 5-mm embryos are considered here.

(i.e., no major repeated up-down cycles through the updraft). These trajectories still result in alternating layers of wet and dry growth, consistent with natural hailstones.

Calculations performed using an idealized 3D squall line reveal only subsevere hail $(<1.5 \mathrm{~cm}$ in maximum dimension, most of which would melt) throughout the storm, despite large updraft speeds. This is consistent with expectations. In contrast, tests using an idealized simulation of the El Reno supercell show significantly severe hail. In both cases, fallout locations are consistent with observations and expectations. These tests demonstrate the trajectory model versatility (i.e., it does not "always" produce large hail) and at least reasonable results based on expectations with different storm modes.

Preliminary varying-shear experiments using the simulated storms from DK17 clarify and extend their results, namely, that increased deep-layer shear ("umax cases") leads to larger and more numerous hail. Using the trajectory calculations, we found that increased hail

size results from trajectories allowing hailstones to have longer residence times in wider updrafts. Similarly, despite larger updraft volumes, the cases with increased meridional low-level shear ("vmax cases") produce smaller hail sizes overall. The trajectory calculations revealed shorter hailstone residence times in updrafts owing to faster advection through the updraft, primarily by the northward branch of the mesocyclone, which is in part a manifestation of the vertical advection of greater low-level meridional storm-relative winds (e.g., Browning 1977). This points to the actions of competing effects: increased shear leads to larger updraft area in the hail growth region (permitting longer trajectories and thus larger sizes), but also increased horizontal wind speeds within the updraft (more rapid advection of hailstones out of the hail growth region). We speculate that environments that provide wide updrafts but relatively weak horizontal flow within the updraft could lead to very large hail as residence time is maximized. The importance of weak horizontal flow in the updraft was also noted by Rasmussen and Heymsfield (1987b). 

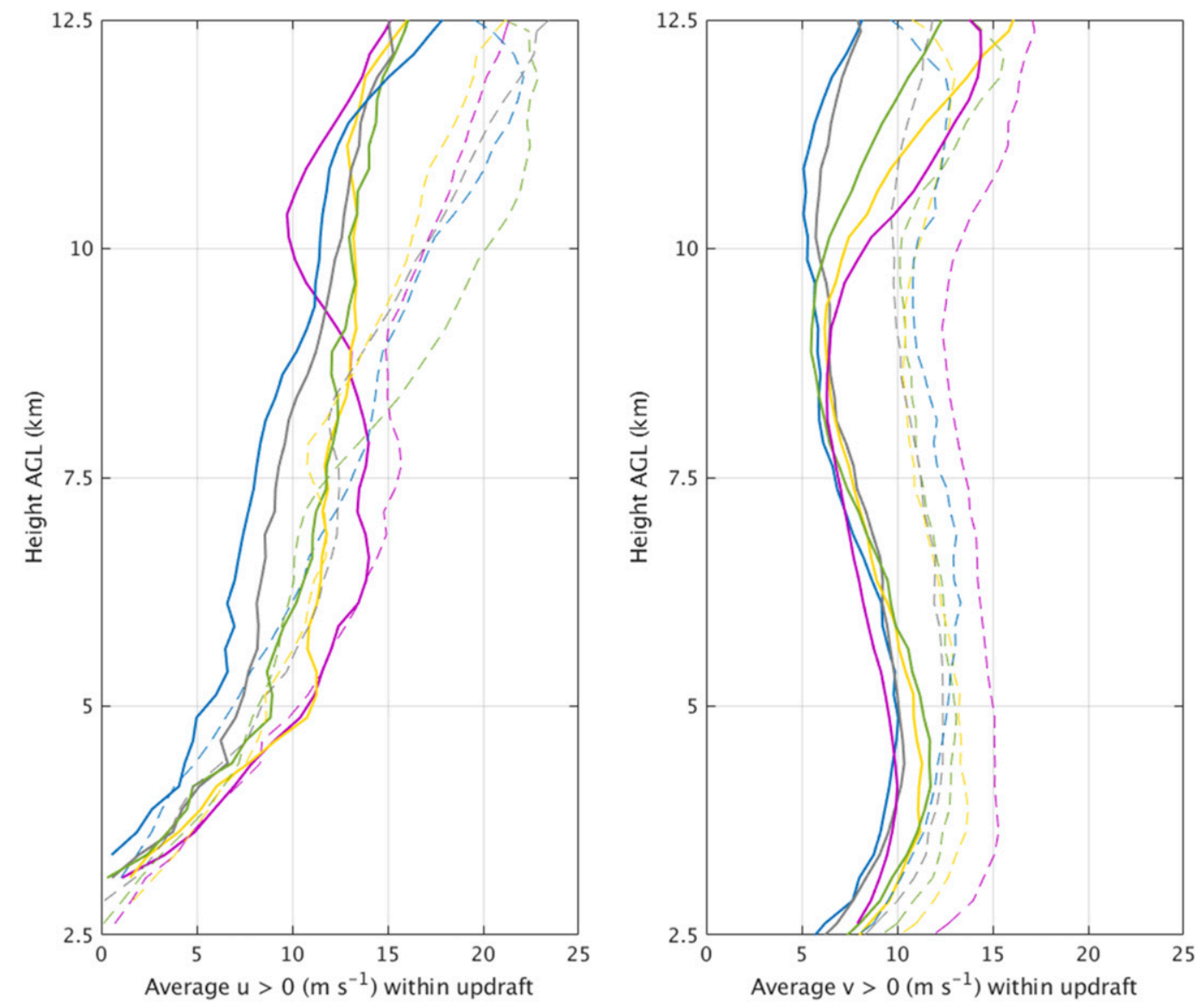

FIG. 13. (left) Mean profiles of $u>0$ conditionally averaged within updraft $w \geq 15 \mathrm{~m} \mathrm{~s}^{-1}$. Solid lines indicate umax cases (with weak meridional low-level shear; vmax $=7 \mathrm{~m} \mathrm{~s}^{-1}$ ), and dashed lines indicate vmax cases (with enhanced meridional low-level shear; vmax $=16 \mathrm{~m} \mathrm{~s}^{-1}$ ). (right) As in the left panel, but for mean profiles of $v>0$.

Numerical simulations should be done to determine what factors affect the airflow patterns specifically within the hail growth region of convective updrafts. Wind shear plays a substantial role (e.g., DK17; Trapp et al. 2017; Warren et al. 2017); we hypothesize that details of the storm-relative hodograph may be important, as well, and will be investigated in future work using this framework.

All but one of the simulated supercells from DK17 tested here produce significantly severe hail $(>5 \mathrm{~cm})$, the exception being the umax 25 vmax16 storm, which produces a maximum size of only $3.5 \mathrm{~cm}$. This result is consistent with findings of Blair et al. (2017) that $90 \%$ of supercells they intercepted in the U.S. Great Plains contained maximum hail sizes $\geq 5 \mathrm{~cm}$, and the remainder had maximum hail sizes $\geq 3.8 \mathrm{~cm}$. The fact that the storms tested here all had the same thermodynamic environments demonstrates that changes to the vertical wind shear can lead to a broad range of maximum hail sizes in storms.
There are a number of uncertain parameters and assumptions in the trajectory model, which require further study and testing. The appendix examines the sensitivity of the hail size results to these uncertainties. Further, the environments studied here and in DK17, Trapp et al. (2017), and Warren et al. (2017) are highly idealized and represent only a small portion of the relevant environmental parameter space for hailstorms; future work will include testing more realistic environments. Nonetheless, our hail growth trajectory model produces reasonable results and thus may be used to provide further insights into the environmental controls on hail size.

Acknowledgments. Funding for this work is from the National Science Foundation Grants AGS-1661679 and AGS-1855063, as well as an award from the Insurance Institute for Business and Home Safety (IBHS). We thank Scott Loeffler (Penn State) for providing the El Reno, Oklahoma, storm simulation 
model output. We are also grateful for discussions with Ian Giammanco (IBHS), Charlie Knight (NCAR), Rebecca Adams-Selin (AER), Conrad Ziegler (NSSL), and John Allen (CMU). Leah Grant (CSU) and two additional anonymous reviewers provided insightful and constructive comments and suggestions that improved the manuscript.

\section{APPENDIX}

\section{Sensitivity Experiments}

Though the model described in our paper produces realistic distributions of hail sizes and fallout locations for different storm modes (i.e., squall line and an intense supercell), there remain a number of uncertain parameters and assumptions that may affect the resulting distribution of hail sizes. We explore these sensitivities here.

\section{a. Methods}

Unless otherwise stated, all sensitivity tests described herein utilize the "umax" and "vmax" cases from above, in which only the vertical wind shear is altered. The control settings for each storm are as before: initial embryos have density $\rho_{i}=917 \mathrm{~kg} \mathrm{~m}^{-3}$; these are initialized at each grid point around the updraft in a $25.5 \mathrm{~km} \times 25.5 \mathrm{~km} \times 7.5 \mathrm{~km}$ region in $x, y$, and $z$, respectively, or 78030 embryos for each test. To facilitate quantitative comparison across the different tests, we define several metrics based on the distribution of hail sizes resulting from these initial embryos. First, we only consider the subset of trajectories that result in hailstone sizes $>1.5 \mathrm{~cm}$ to isolate those that lead to substantial growth. From this subset, we compute the 50th-, 90th-, 95th-, and 99th-percentile sizes, the maximum size, and the number of seeds that result in hailstones with a size exceeding the severe threshold as defined by the U.S. National Weather Service $(>2.54 \mathrm{~cm})$.

It is desirable to have a benchmark for what types of changes to the simulated hail sizes should be considered robust. We ran a series of simulations in which the CM1simulated (background storm) fields were randomly perturbed; in particular, we perturbed the wind field ( $u, v, w$ components) by magnitudes $\leq 2 \mathrm{~m} \mathrm{~s}^{-1}$ in five different trials, and then perturbed the cloud liquid water mass mixing ratio ${ }^{6} q_{c}$ by magnitudes $\leq 1 \mathrm{~g} \mathrm{~kg}^{-1}$ in

\footnotetext{
${ }^{6}$ These perturbations were only applied to where the control simulation had nonzero cloud water mass; when the perturbations caused cloud water mass in a grid box to become negative, it was reset to zero.
}

five different trials. These trials were run for the umax36 storm, with initial embryo diameters of $0.5 \mathrm{~cm}$ and densities of $917 \mathrm{~kg} \mathrm{~m}^{-3}$. The resulting distributions of final hailstone sizes for these random perturbation tests compared to the control run exhibit only minor differences, except for the large-size end of the spectrum (not shown). For the median, 90th-, 95th-, and 99th-percentile metrics, relative differences were $\leq 5 \%$, suggesting that a given storm simulation is robust to small, random fluctuations in the wind or cloud water fields. The maximum size metric exhibited greater variability, with up to a $43 \%$ difference with the control run (though the average across all trials was about $8 \%$ ), implying that using maximum diameter as a metric is more volatile than other metrics when comparing the different tests. The perturbations to the cloud liquid water mass mixing ratio produced larger variability in the maximum hail size than perturbations to the wind field (e.g., Foote 1984; Rasmussen and Heymsfield 1987b; Tuttle et al. 1989), though similar variability in the other metrics. Hereafter, we will consider $>5 \%-10 \%$ changes in the metrics characterizing the hail size distribution across different experiments "robust" (i.e., greater than differences that might be expected from random perturbations to the storm's kinematic and microphysical fields). Given a benchmark for comparison, we now test the hail trajectory model sensitivity to a number of parameters and assumptions as detailed below.

\section{b. Sensitivity tests}

\section{1) EMBRYO SIZE}

First, we explore how initial embryo size affects the resulting distribution of hail sizes. We tested embryos with 2.5-, 5.0-, 7.5-, and 10.0-mm diameters for each of the five umax storms (Figs. A1a-e). In general, larger initial embryos tend to result in greater hailstone sizes (e.g., Ziegler et al. 1983; Foote 1984; ASZ16). Additionally, for a given storm, larger-sized embryos result in greater numbers of hailstones that exceed the severe threshold $(>2.54 \mathrm{~cm}$; Fig. A1f). These results also are consistent with Foote (1984), who found that embryos of a given size result in a wide variety of final hailstone sizes, and that severe hail may arise from embryos of small initial sizes. The figure also shows the tendency for hail size and number of severe-sized stones to increase with increasing deep-layer vertical wind shear, regardless of embryo size. Given the large sensitivity to embryo size, hail growth trajectory modeling should account for a range of initial embryo sizes, as suggested by Ziegler et al. (1983) and Foote (1984), and as we did in section $3 \mathrm{c}$. 

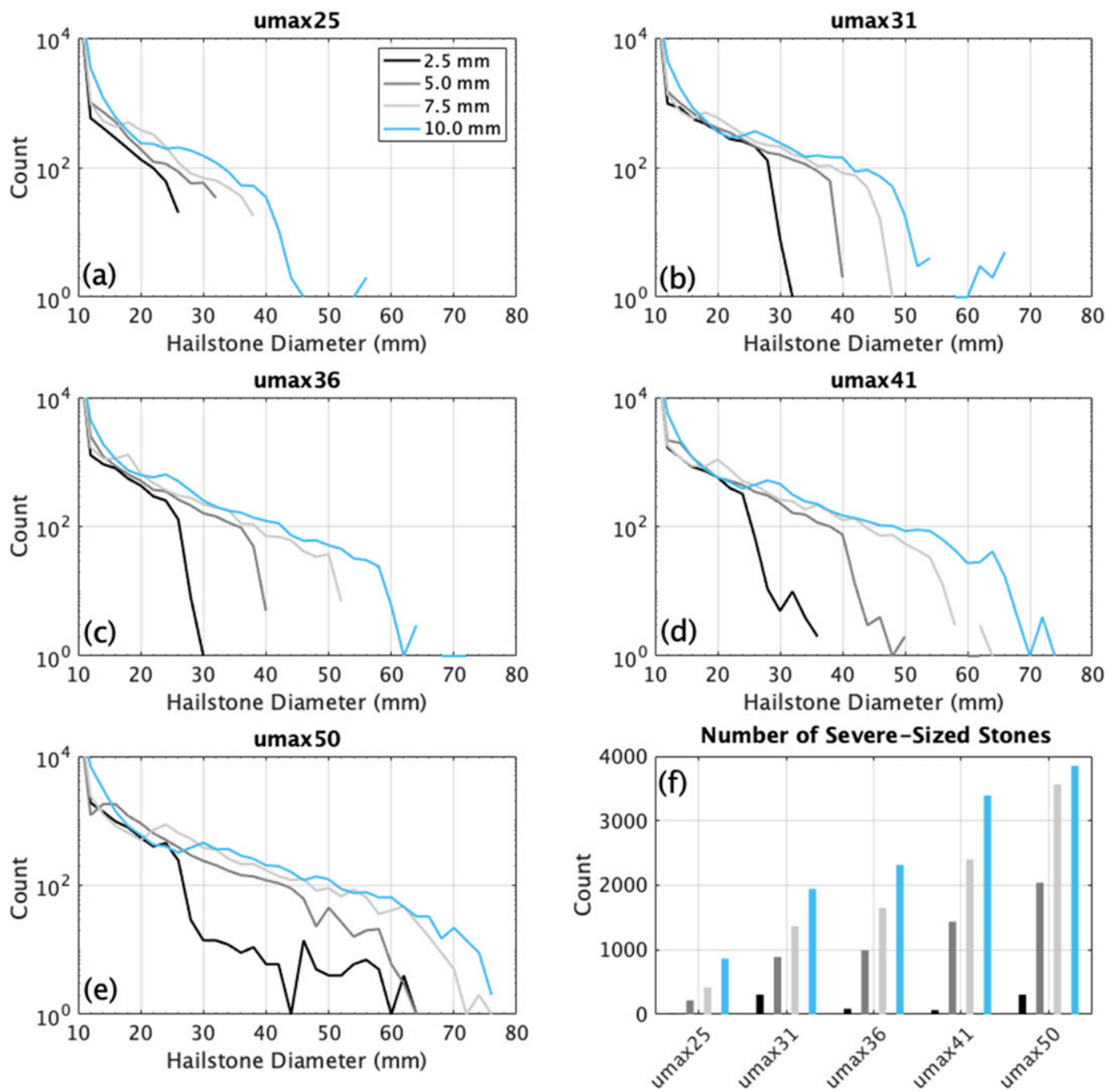

FIG. A1. Distribution of hailstone diameters resulting from embryos of 2.5 (black), 5.0 (dark gray), 7.5 (light gray), and $10.0 \mathrm{~mm}$ (light blue) for the (a) umax 25, (b) umax31, (c) umax36, (d) umax41, and (e) umax50 storms. (f) The number of stones that exceed severe size $(>25.4 \mathrm{~mm})$ for each storm, with each bar representing embryos of the size indicated by colors (as in previous panels).

\section{2) EMBRYO DENSITY}

The previous tests have assumed initial embryo density is that of solid ice, such that embryos resemble something like frozen raindrops. Though frozen raindrops are known to play an important role as hailstone embryos (e.g., Knight 1981; Rasmussen and Heymsfield 1987b), lower-density particles like graupel are probably more common as embryos (Knight 1981). Thus, we repeat the same tests as before, but with the initial embryo density set to $500 \mathrm{~kg} \mathrm{~m}^{-3}$. This has the effect of decreasing embryo fall speeds and allowing initial liquid from wet growth to soak into the particle's interior (see the main text). Figure A2 shows the relative changes in the hail size metrics between the high- and reduced-density embryos as a function of initial embryo diameter, color-coded by storm simulation. Hereafter, we festively refer to these as "confetti plots." For the median, 90th-, 95th-, and 99th-percentile sizes (Figs. A2a-d), relative changes are predominantly negative and small $(<10 \%)$. This means that reducing embryo density leads to an insignificant decrease in the resulting distribution of hail sizes. The relative changes for maximum size (Fig. A2e) and number of severe-sized stones (Fig. A2f) show somewhat more robust changes. There is no clear trend in maximum size across storms or embryo sizes (recall this metric is the most volatile). In contrast, the smallestsized initial embryos result in substantial reductions in the number of hailstones that grow to severe size in all storms. Such small, low-density embryos fall slower and 

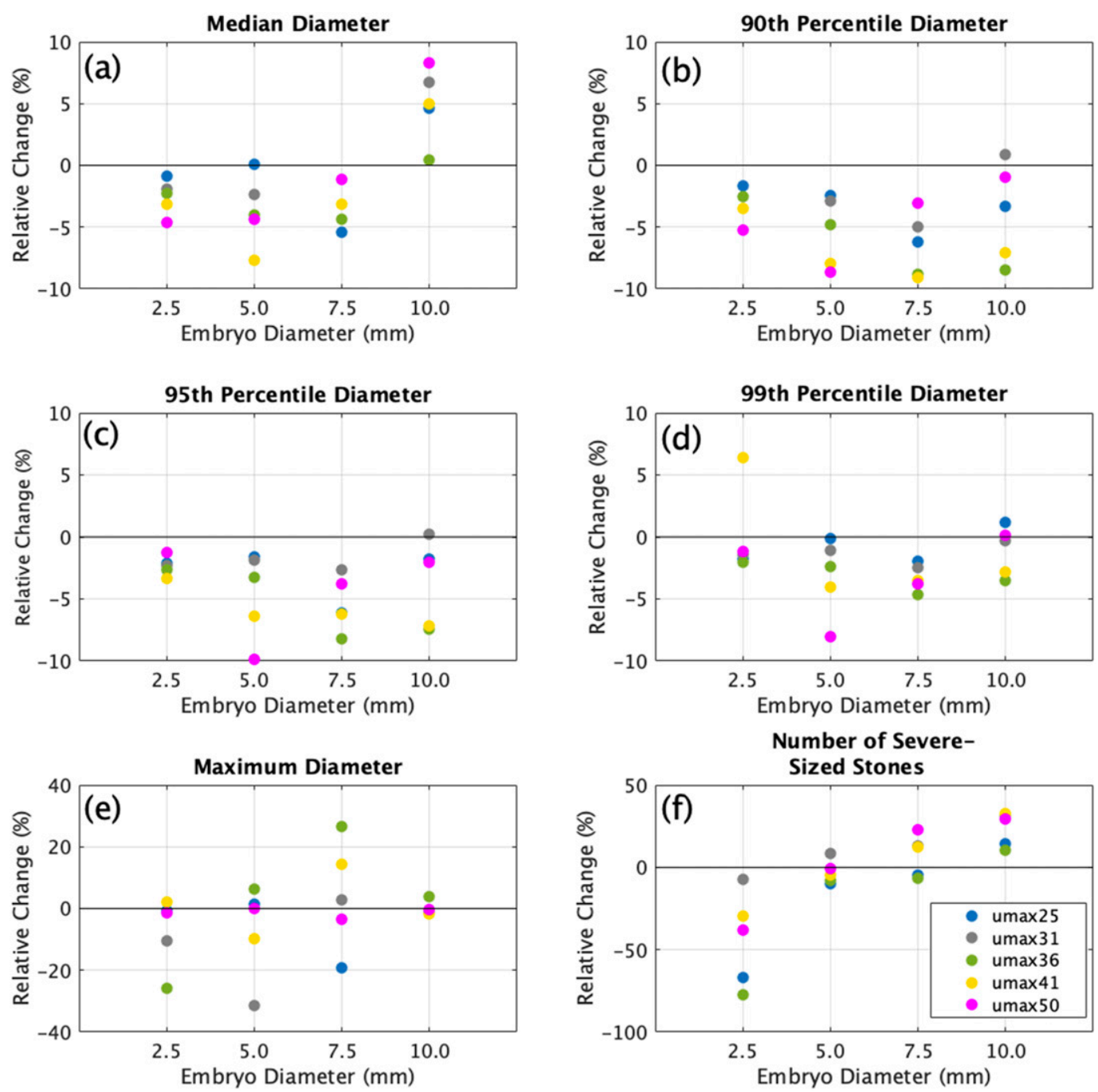

FIG. A2. Confetti plot showing the relative change in hail size metrics between the solid-ice embryo and reduced-density $\left(500 \mathrm{~kg} \mathrm{~m}^{-3}\right)$ embryo as a function of embryo size (abscissa of each panel) and storm (color coded: umax 25 in blue, umax31 in gray, umax36 in green, umax 41 in goldenrod, and umax50 in magenta). Hail metrics shown are (a) median size, (b) 90th-percentile size, (c) 95th-percentile size, (d) 99th-percentile size, (e) maximum size, and (f) number of stones exceeding severe size $(>25.4 \mathrm{~mm})$. Note the changes to ordinate axes in (e) and (f).

are advected much farther by the storm-relative winds; thus, in order to realize significant growth, these embryos would have to initiate much farther upwind of the storm and out of the initial block that was seeded (i.e., unrealistically far from the storm). Of course, feeder cells or other storms in the vicinity can provide embryos (Heymsfield 1983), though these are not considered in the present study. Larger initial sizes $(7.5,10.0 \mathrm{~mm})$ of reduced-density embryos lead to larger numbers of severe-sized hailstones (Fig. A2f) because more embryos from the initial seeded field can ingested into the updraft owing to their reduced fall speeds (i.e., those initially farther from the updraft have more time to be advected into the updraft by the storm-relative winds and inflow).

\section{3) DRAg COEFFICIENT}

The fall speeds and behavior of hailstones has been of recent interest (e.g., Heymsfield and Wright 2014; Heymsfield et al. 2014, 2018), in part because the fall speed plays a significant role in determining the hailstone's damage potential. In most models, including ours, the hailstone fall speed is a function of the drag coefficient $C_{D}$. Recall we used a control value of $C_{D}=$ 0.5 in the main text. Here, we vary $C_{D}$ from 0.1 to 1.0 (Fig. A3). The results indicate more substantial 

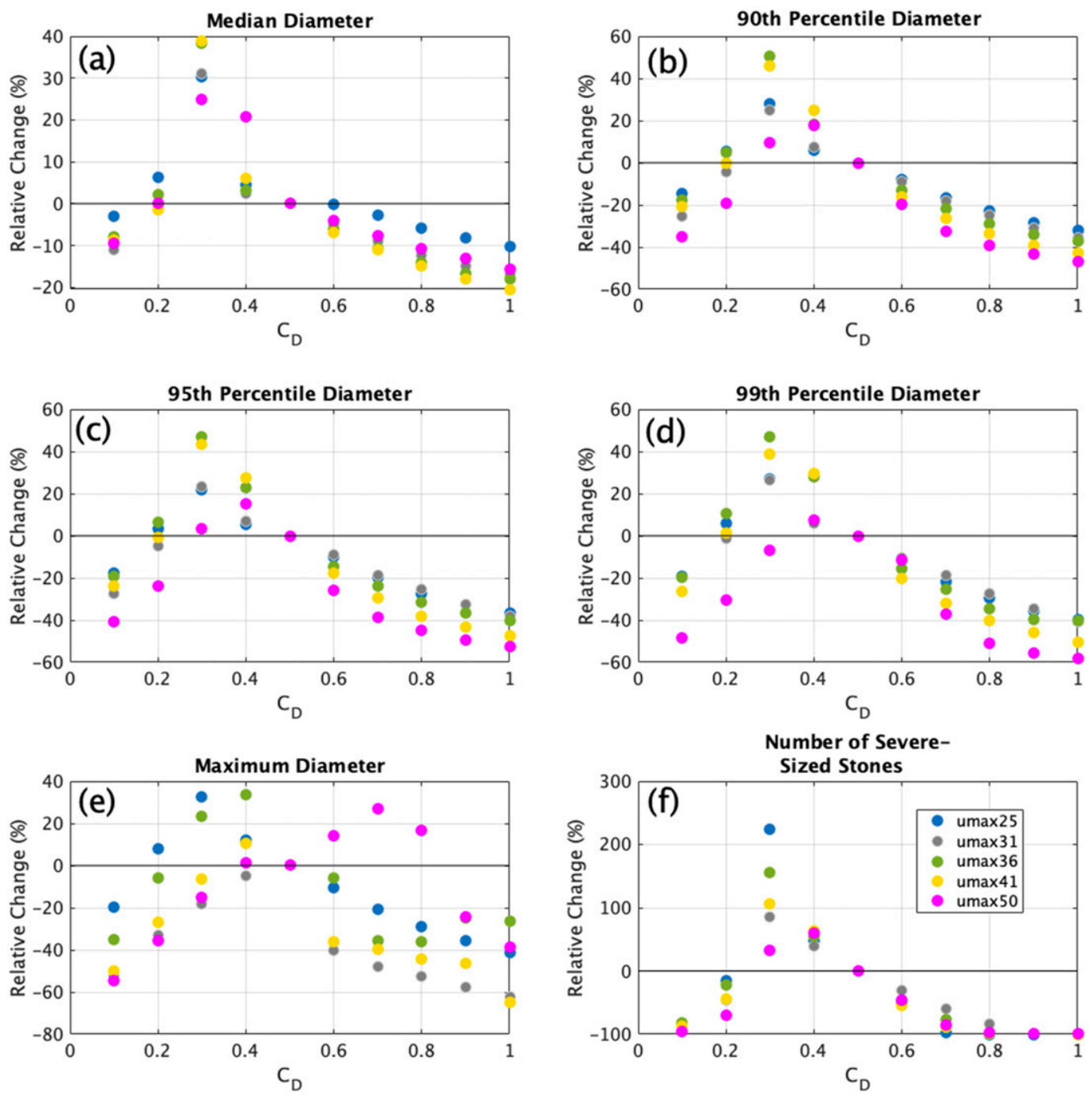

FIG. A3. Confetti plot showing the relative change in hail size metrics as a function of drag coefficient $C_{D}$ for each storm. The control $C_{D}$ value is 0.5 . Embryos are all $5 \mathrm{~mm}$ in diameter with density equal to that of solid ice.

sensitivity of the hail metrics to the drag coefficient: outside of a narrow range between about $0.3-0.4$, the relative changes are negative, indicating substantial reductions in hail size with both increased and decreased $C_{D}$. This translates to reductions in hail size for both faster- and slower-falling hailstones, emphasizing the balance between hailstone fall speed and updraft needed for growth: particles falling too fast are unable to be swept into the updraft or spend as much time there, whereas slower-falling particles are lofted out of the hail growth region too quickly. It is possible that $C_{D}$ changes throughout the hailstone's growth history; however, given the highly uncertain $C_{D}$ values for natural hailstones (e.g., Heymsfield et al. 2018), such an exploration is beyond the scope of this paper.

\section{4) Collection EFFICIENCIES}

Because collection of supercooled cloud droplets is the primary mechanism by which hailstones grow, we expect large sensitivities to the value of the cloud droplet collection efficiency, $E_{\mathrm{cc}}$. Figure A4 reveals substantial reductions in hail sizes for reduced $E_{\mathrm{cc}}$, including some simulations that failed to produce any hail $>1.5 \mathrm{~cm}$ (i.e., those with $100 \%$ relative changes to a given hail metric). The results also show that, in order to get any appreciable concentration of severe-sized hailstones, $E_{\mathrm{cc}}$ must be $>0.8$ (Fig. A4f). For the $E_{\mathrm{cc}}=0$ tests, a few ( $<5$ for each storm) "lucky" embryos are able to grow somewhat by collection of rainwater, though in practice these are probably insignificant. 



FIG. A4. Confetti plot showing the relative change in hail size metrics as a function of cloud droplet collection efficiency $E_{\mathrm{cc}}$ for each storm. The control setting is $E_{\mathrm{cc}}=1$ except for the smallest cloud droplet mean-mass diameters (see text). Embryos are all $5 \mathrm{~mm}$ in diameter with density equal to that of solid ice.

How effectively hailstones collect supercooled raindrops is essentially unknown. Given the far lower number concentration of raindrops compared to cloud droplets, it is expected that raindrop collection is of lesser importance to hail growth than cloud droplet collection. For this reason, most studies neglect raindrop collection (e.g., ASZ16). However, the presence of supercooled raindrops in the lower portion of the hail growth zone is well known from polarimetric radar observations and modeling (e.g., Kumjian et al. 2014, and references therein), so we suggest its inclusion is warranted. In the main text, we used a fixed value of the raindrop collection efficiency $E_{\text {cr }}=0.8$. The sensitivity to this parameter is shown in Fig. A5. As expected, reducing $E_{\mathrm{cr}}$ toward 0 results in smaller hail metrics, albeit insignificant relative changes for median size (Fig. A5a). Disallowing rain collection entirely leads to up to $20 \%$ smaller 90th-, 95th-, and 99th-percentile sizes (Figs. A5b-d). The relative changes are larger in magnitude for the maximum size and number concentration of severe hailstones (Figs. A5e,f): setting $E_{\mathrm{cr}}=0$ (as is commonly done) leads to $>30 \%$ reductions in the number concentration of severe hail for all shear cases. This suggests collection of raindrops may be an important microphysical process and should be considered in hail growth models.

The conditions under which hailstones collect ice crystals - if at all — are highly uncertain (see the discussion in the main text). To explore the sensitivity to this uncertainty, we run tests using four different parameterizations 

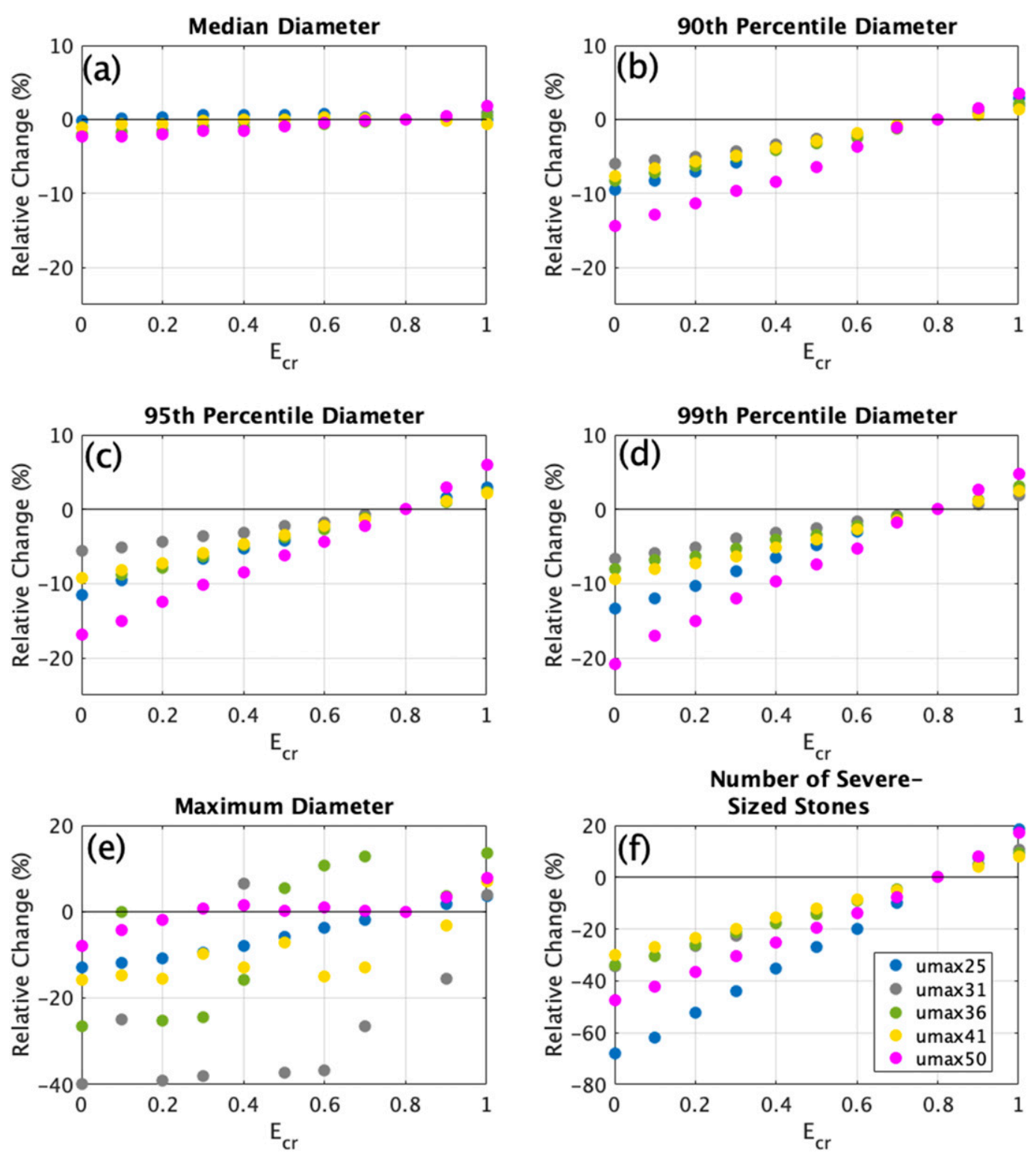

FIG. A5. Confetti plot showing the relative change in hail size metrics as a function of raindrop collection efficiency $E_{\mathrm{cr}}$ for each storm. The control setting is $E_{\mathrm{cr}}=0.8$. Embryos are all $5 \mathrm{~mm}$ in diameter with density equal to that of solid ice.

for the ice collection efficiency $E_{\mathrm{ci}}$ : fixed values of $E_{\mathrm{ci}}=$ 0.0 (i.e., ice collection is not permitted) and $E_{\mathrm{ci}}=1.0$ (i.e., all ice contacting the hailstone is incorporated), and two temperature-dependent formulations from the HAILCAST model, including its original ("Old"; Jewell and Brimelow 2009) and updated (ASZ16) formulations. In the "Old" formulation, $E_{\mathrm{ci}}$ decreases as a step function from unity for temperatures $>-5^{\circ}$ to 0.21 for temperatures $<-5^{\circ} \mathrm{C}$, whereas in ASZ16, $E_{\mathrm{ci}}$ decreases linearly from unity at $0^{\circ} \mathrm{C}$ to zero at $-40^{\circ} \mathrm{C}$, as in Ziegler et al. (1983). Recall that the control parameterization used in the main text sets $E_{\mathrm{ci}}=1.0$ only during wet growth, and otherwise is set to 0 . The relative changes in the resulting median, 90th-, 95th-, and 99th-percentile hail sizes (Figs. A6a-d) are insignificant. The relative change magnitudes are larger for the maximum size (Fig. A6e), but do not display any consistent pattern with vertical wind shear. There are somewhat larger $(<40 \%)$ increases in the number of hailstones exceeding the severe size threshold when setting $E_{\mathrm{ci}}=1.0$ (Fig. A6f), suggesting that some additional embryos can attain large sizes in otherwise 

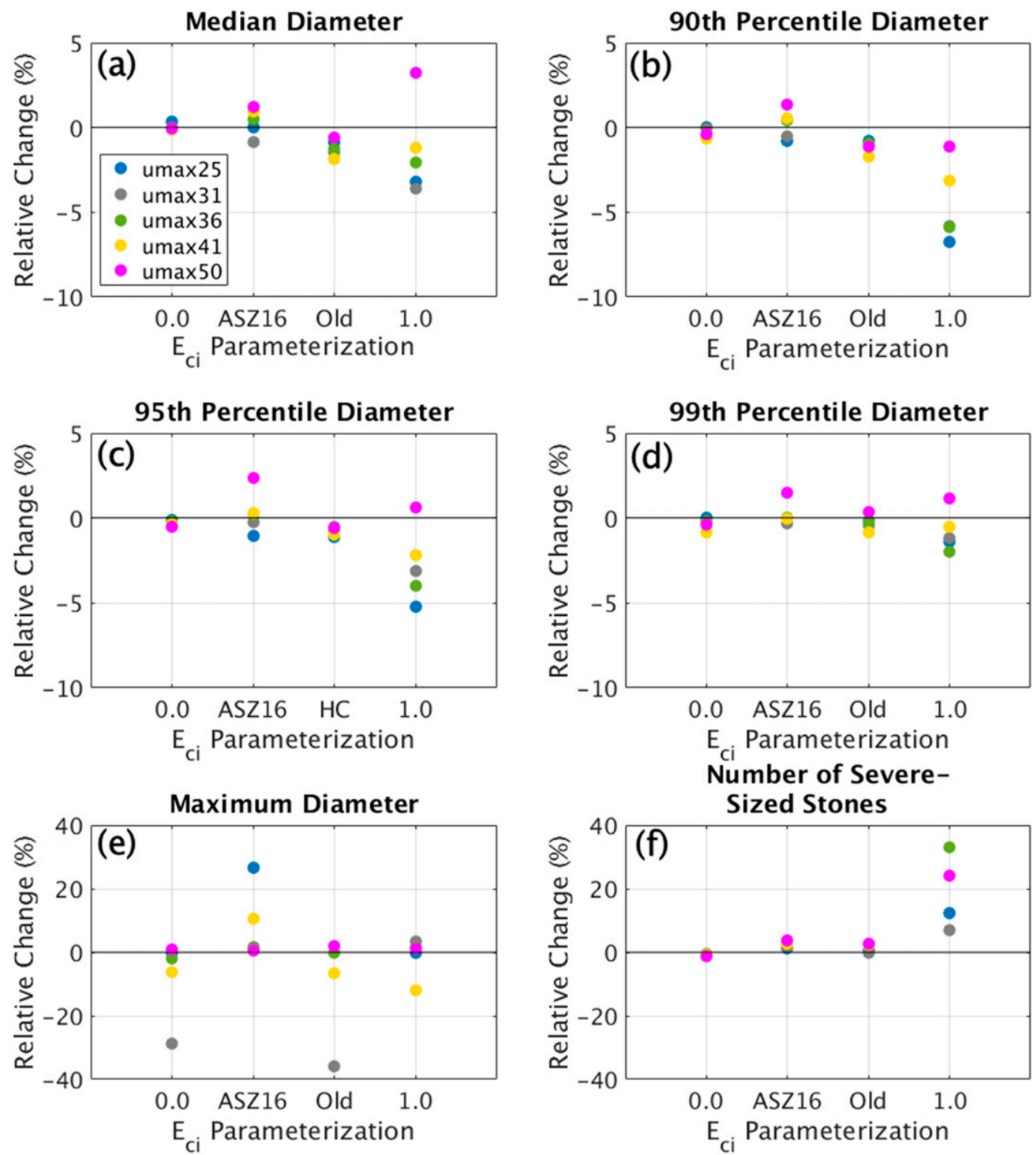

FIG. A6. Confetti plot showing the relative change in hail size metrics as a function of ice collection efficiency $E_{\mathrm{ci}}$ parameterization for each storm. The control setting is $E_{\mathrm{ci}}=0$, except during wet growth when $E_{\mathrm{ci}}=1$. The other parameterizations are $E_{\mathrm{ci}}=0$ (i.e., no ice collection permitted), "ASZ16" (the current HAILCAST formulation), "Old" (the previous HAILCAST formulation), and $E_{\mathrm{ci}}=1.0$ (i.e., ice collection always permitted). Embryos are all $5 \mathrm{~mm}$ in diameter with density equal to that of solid ice.

unfavorable conditions (i.e., outside of regions of significant supercooled liquid water) when ice collection is always permitted; however, as discussed above, we believe such a formulation is unphysical.

\section{REFERENCES}

Adams-Selin, R., and C. L. Ziegler, 2016: Forecasting hail using a one-dimensional hail growth model within WRF. Mon. Wea. Rev., 144, 4919-4939, https://doi.org/10.1175/ MWR-D-16-0027.1.
Allen, J. T., and M. K. Tippett, 2015: The characteristics of United States hail reports: 1955-2014. Electron. J. Severe Storms Meteor., 10 (3), https://ejssm.org/ojs/index.php/ejssm/article/viewArticle/149.

Asakawa, H., G. Sazaki, K. Nagashima, S. Nakatsubo, and Y. Furukawa, 2016: Two types of quasi-liquid layers on ice crystals are formed kinetically. Proc. Natl. Acad. Sci. USA, 113, 1749-1753, https://doi.org/10.1073/pnas.1521607113.

Bailey, I. H., and W. C. Macklin, 1968: Heat transfer from artificial hailstones. Quart. J. Roy. Meteor. Soc., 94, 93-98, https:// doi.org/10.1002/qj.49709439910.

Blair, S. F., D. R. Deroche, J. M. Boustead, J. W. Leighton, B. L. Barjenbruch, and W. P. Gargan, 2011: A radar-based assessment 
of the detectability of giant hail. Electron. J. Severe Storms Meteor., 6 (7), https://ejssm.org/ojs/index.php/ejssm/article/ viewArticle/87

—, and Coauthors, 2017: High-resolution hail observations: Implications for NWS warning operations. Wea. Forecasting, 32, 1101-1119, https://doi.org/10.1175/WAF-D-16-0203.1.

Brandes, E. A., G. Zhang, and J. Vivekanandan, 2002: Experiments in rainfall estimation with a polarimetric radar in a subtropical environment. J. Appl. Meteor., 41, 674-685, https://doi.org/ 10.1175/1520-0450(2002)041<0674:EIREWA > 2.0.CO;2.

Brimelow, J. C., G. W. Reuter, and E. R. Poolman, 2002: Modeling maximum hail size in Alberta thunderstorms. Wea. Forecasting, 17, 1048-1062, https://doi.org/10.1175/1520-0434(2002)017<1048: MMHSIA $>2.0 . \mathrm{CO} ; 2$.

Browning, K. A., 1964: Airflow and precipitation trajectories with severe local storms which travel to the right of the winds. J. Atmos. Sci., 21, 634-639, https://doi.org/10.1175/ 1520-0469(1964)021<0634:AAPTWS >2.0.CO;2.

_, 1977: The structure and mechanisms of hailstorms. Hail: A Review of Hail Science and Hail Suppression, Meteor. Monogr. No. 38, Amer. Meteor. Soc., 1-43.

- and G. B. Foote, 1976: Air-flow and hail growth in supercell storms and some implications for hail suppression. Quart. J. Roy. Meteor. Soc., 102, 499-533, https://doi.org/10.1002/ qj. 49710243303.

Bryan, G. H., and J. M. Fritsch, 2002: A benchmark simulation for moist nonhydrostatic numerical models. Mon. Wea. Rev., 130, 2917-2928, https://doi.org/10.1175/1520-0493(2002)130<2917: ABSFMN $>2.0 . \mathrm{CO} ; 2$.

Carbone, R. E., 1982: A severe frontal rainband. Part I: Stormwide hydrodynamic structure. J. Atmos. Sci., 39, 258-279, https://doi.org/10.1175/1520-0469(1982)039<0258: ASFRPI $>2.0 . \mathrm{CO} ; 2$.

Chalon, J.-P., J. C. Fankhauser, and P. J. Eccles, 1976: Structure of an evolving hailstorm. Part I: General characteristics and cell structure. Mon. Wea. Rev., 104, 564-575, https://doi.org/ 10.1175/1520-0493(1976)104<0564:SOAEHP > 2.0.CO;2.

Changnon, S., D. Changnon, and S. D. Hilberg, 2009: Hailstorms across the nation: An atlas about hail and its damages. Illinois State Water Survey Contract Rep. 2009-12, 92 pp., https:// www.isws.illinois.edu/pubdoc/CR/ISWSCR2009-12.pdf.

Cintineo, J. L., T. M. Smith, V. Lakshmanan, H. E. Brooks, and K. L. Ortega, 2012: An objective high-resolution hail climatology of the contiguous United States. Wea. Forecasting, 27, 1235-1248, https://doi.org/10.1175/WAF-D-11-00151.1.

Dennis, A. S., C. A. Schock, and A. Koscielski, 1970: Characteristics of hailstorms of western South Dakota. J. Appl. Meteor., 9, 127-135, https://doi.org/10.1175/1520-0450(1970)009<0127: COHOWS $>2.0$.CO;2.

Dennis, E. J., and M. R. Kumjian, 2017: The impact of vertical wind shear on hail growth in simulated supercells. J. Atmos. Sci., 74, 641-663, https://doi.org/10.1175/JAS-D-16-0066.1.

Edwards, R., and R. L. Thompson, 1998: Nationwide comparisons of hail size with WSR-88D vertically integrated liquid water and derived thermodynamic sounding data. Wea. Forecasting, 13, 277-285, https://doi.org/10.1175/1520-0434(1998) $013<0277$ :NCOHSW $>2.0 . \mathrm{CO} ; 2$.

Ewing, G. E., 2004: Thin film water. J. Phys. Chem., 108B, $15953-$ 15 961, https://doi.org/10.1021/jp040378+.

Federer, B., B. Thalmann, and J. Jouzel, 1982: Stable isotopes in hailstones. Part II: Embryo and hailstone growth in different storms. J. Atmos. Sci., 39, 1336-1355, https://doi.org/10.1175/ 1520-0469(1982)039<1336:SIIHPI >2.0.CO;2.
Foote, G. B., 1984: A study of hail growth utilizing observed storm conditions. J. Climate Appl. Meteor., 23, 84-101, https://doi.org/ 10.1175/1520-0450(1984)023<0084:ASOHGU>2.0.CO;2.

French, M. M., H. B. Bluestein, I. PopStefanija, C. A. Baldi, and R. T. Bluth, 2013: Reexamining the vertical development of tornadic vortex signatures in supercells. Mon. Wea. Rev., 141, 4576-4601, https://doi.org/10.1175/MWR-D-12-00315.1.

P. S. Skinner, L. J. Wicker, and H. B. Bluestein, 2015: Documenting a rare tornado merger observed in the 24 May 2011 El Reno-Piedmont, Oklahoma, supercell. Mon. Wea. Rev., 143, 3025-3043, https://doi.org/10.1175/MWR-D-14-00349.1.

Friedrich, K., and Coauthors, 2019: CHAT: The Colorado Hail Accumulation from Thunderstorms project. Bull. Amer. Meteor. Soc., 100, 459-471, https://doi.org/10.1175/BAMS-D-16-0277.1.

Gagne, D. J., A. McGovern, S. E. Haupt, R. A. Sobash, J. K. Williams, and M. Xue, 2017: Storm-based probabilistic hail forecasting with machine learning applied to convectionallowing ensembles. Wea. Forecasting, 32, 1819-1840, https:// doi.org/10.1175/WAF-D-17-0010.1.

Grant, L. D., and S. C. van den Heever, 2014: Microphysical and dynamical characteristics of low-precipitation and classic supercells. J. Atmos. Sci., 71, 2604-2624, https://doi.org/10.1175/ JAS-D-13-0261.1.

Groenemeijer, P. H., and A. van Delden, 2007: Sounding-derived parameters associated with large hail and tornadoes in the Netherlands. Atmos. Res., 83, 473-487, https://doi.org/10.1016/ j.atmosres.2005.08.006.

Gunturi, P., and M. Tippett, 2017: Managing severe thunderstorm risk: Impact of ENSO on U.S. tornado and hail frequencies. Willis Re Tech. Rep., 5 pp., http://www.columbia.edu/ mkt14/ files/WillisRe_Impact_of_ENSO_on_US_Tornado_and_Hail_ frequencies_Final.pdf.

Gutierrez, R., and M. R. Kumjian, 2018: Environmental and radar characteristics of gargantuan hail-producing storms. 29th Conf. on Severe Local Storms, Stowe, VT, Amer. Meteor. Soc., 13A.5, https://ams.confex.com/ams/29SLS/webprogram/ Paper348569.html.

Heymsfield, A. J., 1983: Case-study of a hailstorm in Colorado. Part IV: Graupel and hail growth mechanisms deduced through particle trajectory calculations. J. Atmos. Sci., 40, 1482-1509, https:// doi.org/10.1175/1520-0469(1983)040<1482:CSOAHI >2.0.CO;2. , and J. C. Pflaum, 1985: A quantitative assessment of the accuracy of techniques for calculating graupel growth. J. Atmos. Sci., 42, 2264-2274, https://doi.org/10.1175/1520-0469(1985) 042<2264:AQAOTA $>2.0 . \mathrm{CO} ; 2$.

, and R. Wright, 2014: Graupel and hail terminal velocities: Does a "supercritical" Reynolds number apply? J. Atmos. Sci., 71, 3392-3403, https://doi.org/10.1175/JAS-D-14-0034.1.

—, A. R. Jameson, and H. W. Frank, 1980: Hail growth mechanisms in a Colorado hailstorm. Part II: Hail formation processes. J. Atmos. Sci., 37, 1779-1807, https://doi.org/10.1175/ 1520-0469(1980)037<1779:HGMIAC >2.0.CO;2.

, I. M. Giammanco, and R. Wright, 2014: Terminal velocities and kinetic energies of natural hailstones. Geophys. Res. Lett., 41, 8666-8672, https://doi.org/10.1002/2014GL062324.

—, M. Szakáll, A. Jost, I. Giammanco, and R. Wright, 2018: A comprehensive observational study of graupel and hail terminal velocity, mass flux, and kinetic energy. J. Atmos. Sci., 75, 3861-3885, https://doi.org/10.1175/JAS-D-18-0035.1.

Hosler, C. L., D. C. Jensen, and L. Goldshlak, 1957: On the aggregation of ice crystals to form snow. J. Meteor., 14, 415-420, https://doi.org/10.1175/1520-0469(1957)014<0415: OTAOIC $>2.0 . \mathrm{CO} ; 2$. 
Jewell, R., and J. Brimelow, 2009: Evaluation of Alberta hail growth model using severe hail proximity soundings from the United States. Wea. Forecasting, 24, 1592-1609, https:// doi.org/10.1175/2009WAF2222230.1.

Johnson, A. W., and K. E. Sugden, 2014: Evaluation of soundingderived thermodynamic and wind-related parameters associated with large hail events. Electron. J. Severe Storms Meteor., 9 (5), https://www.ejssm.org/ojs/index.php/ejssm/ article/viewArticle/137.

Kahraman, A., S. Tilev-Tanriover, M. Kadioglu, D. M. Schultz, and P. M. Markowski, 2016: Severe hail climatology in Turkey. Mon. Wea. Rev., 144, 337-346, https://doi.org/ 10.1175/MWR-D-15-0337.1.

Kalina, E. A., K. Friedrich, B. C. Motta, W. Deierling, G. T. Stano, and N. N. Rydell, 2016: Colorado plowable hailstorms: Synoptic weather, radar, and lightning characteristics. Wea. Forecasting, 31, 663-693, https://doi.org/10.1175/WAF-D-15-0037.1.

Kaltenböeck, R., G. Diendofer, and N. Dotzek, 2009: Evaluation of thunderstorm indices from ECMWF analyses, lightning data, and severe storms reports. Atmos. Res., 93, 381-396, https:// doi.org/10.1016/j.atmosres.2008.11.005.

Knight, C. A., and N. C. Knight, 2005: Very large hailstones from Aurora, Nebraska. Bull. Amer. Meteor. Soc., 86, 1773-1782, https://doi.org/10.1175/BAMS-86-12-1773.

Knight, N. C., 1981: The climatology of hail embryos. J. Appl. Meteor., 20, 750-755, https://doi.org/10.1175/1520-0450(1981) $020<0750$ :TCOHE $>2.0$. CO 2 .

Kumjian, M. R., and A. V. Ryzhkov, 2008: Polarimetric signatures in supercell thunderstorms. J. Appl. Meteor. Climatol., 47, 1940-1961, https://doi.org/10.1175/2007JAMC1874.1.

_ A. P. Khain, N. BenMoshe, E. Ilotoviz, A. V. Ryzhkov, and V. T. J. Phillips, 2014: The anatomy and physics of $Z_{\mathrm{DR}}$ J. Appl. Meteor. Climatol., 53, 1820-1843, https://doi.org/ 10.1175/JAMC-D-13-0354.1.

— Z Z. J. Lebo, and A. A. Ward, 2019: Storms producing large accumulations of small hail. J. Appl. Meteor. Climatol., 58, 341-364, https://doi.org/10.1175/JAMC-D-18-0073.1.

—, and Coauthors, 2020: Gargantuan hail in Argentina. Bull. Amer. Meteor. Soc., https://doi.org/10.1175/BAMS-D-19-0012.1, conditionally accepted.

Kuroda, T., and R. Lacmann, 1982: Growth kinetics of ice from the vapour phase and its growth forms. J. Cryst. Growth, 56, 189-205, https://doi.org/10.1016/0022-0248(82)90028-8.

Lamb, D., and J. Verlinde, 2011: Physics and Chemistry of Clouds. 1st ed. Cambridge University Press, $584 \mathrm{pp}$.

Lesins, G. B., and R. List, 1986: Sponginess and drop shedding of gyrating hailstones in a pressure-controlled icing wind tunnel. J. Atmos. Sci., 43, 2813-2825, https://doi.org/10.1175/15200469(1986)043<2813:SADSOG > 2.0.CO;2.

Letkewicz, C. E., and M. D. Parker, 2010: Forecasting the maintenance of mesoscale convective systems crossing the Appalachian Mountains. Wea. Forecasting, 25, 1179-1195, https://doi.org/ 10.1175/2010WAF2222379.1.

Lombardo, K. A., and B. Colle, 2012: Ambient conditions associated with the maintenance and decay of quasi-linear convective systems crossing the northeastern U.S. coast. Mon. Wea. Rev., 140, 3805-3819, https://doi.org/10.1175/MWR-D-12-00050.1.

, and T. Kading, 2018: The behavior of squall lines in horizontally heterogeneous coastal environments. J. Atmos. Sci., 75, 1243-1269, https://doi.org/10.1175/JAS-D-17-0248.1.

Macklin, W. C., 1963: Heat transfer from hailstones. Quart. J. Roy. Meteor. Soc., 89, 360-369, https://doi.org/10.1002/ qj. 49708938107.
— , and I. H. Bailey, 1966: On the critical liquid water concentrations of large hailstones. Quart. J. Roy. Meteor. Soc., 92, 297-300, https://doi.org/10.1002/qj.49709239215.

Markowski, P. M., and Y. P. Richardson, 2010: Mesoscale Meteorology in Midlatitudes. 1st ed. Wiley-Blackwell, 407 pp.

McCaul, E., and C. Cohen, 2002: The impact on simulated storm structure and intensity of variations in the mixed layer and moist layer depths. Mon. Wea. Rev., 130, 1722-1748, https://doi.org/ 10.1175/1520-0493(2002)130<1722:TIOSSS>2.0.CO;2.

Miller, L. J., and J. C. Fankhauser, 1983: Radar echo structure, air motion and hail formation in a large stationary multicellular thunderstorm. J. Atmos. Sci., 40, 2399-2418, https://doi.org/ 10.1175/1520-0469(1983)040<2399:RESAMA>2.0.CO;2.

—_, J. D. Tuttle, and C. A. Knight, 1988: Airflow and hail growth in a severe Northern Plains supercell. J. Atmos. Sci., 45, 736-762, https://doi.org/10.1175/1520-0469(1988)045<0736: AAHGIA $>2.0 . \mathrm{CO} ; 2$.

- —, and G. B. Foote, 1990: Precipitation production in a large Montana hailstorm: Airflow and particle growth trajectories. J. Atmos. Sci., 47, 1619-1646, https://doi.org/10.1175/ 1520-0469(1990)047<1619:PPIALM>2.0.CO;2.

Morrison, H., J. A. Curry, and V. I. Khvorostyanov, 2005: A new double-moment microphysics parameterization for application in cloud and climate models. Part I: Description. J. Atmos. Sci., 62, 1665-1677, https://doi.org/10.1175/JAS3446.1.

- G. Thompson, and V. Tatarskii, 2009: Impact of cloud microphysics on the development of trailing stratiform precipitation in a simulated squall line: Comparison of one- and two-moment schemes. Mon. Wea. Rev., 137, 991-1007, https://doi.org/ 10.1175/2008MWR2556.1.

_- J. A. Milbrandt, G. H. Bryan, K. Ikeda, S. A. Tessendorf, and G. Thompson, 2015: Parameterization of cloud microphysics based on the prediction of bulk ice particle properties. Part II: Case study comparisons with observations and other schemes. J. Atmos. Sci., 72, 312-339, https:// doi.org/10.1175/JAS-D-14-0066.1.

Murillo, E. M., and C. R. Homeyer, 2019: Severe hail fall and hailstorm detection using remote sensing observations. J. Appl. Meteor. Climatol., 58, 947-970, https://doi.org/ 10.1175/JAMC-D-18-0247.1.

Musil, D. J., A. J. Heymsfield, and P. L. Smith, 1986: Microphysical characteristics of a well-developed weak echo region in a highplains supercell thunderstorm. J. Climate Appl. Meteor., 25, 1037-1051, https://doi.org/10.1175/1520-0450(1986)025<1037: MCOAWD > 2.0.CO;2.

Nelson, S. P., 1983: The influence of storm flow structure on hail growth. J. Atmos. Sci., 40, 1965-1983, https://doi.org/10.1175/ 1520-0469(1983)040<1965:TIOSFS > 2.0.CO;2.

__, 1987: The hybrid multicellular-supercellular storm-An efficient hail producer. Part II: General characteristics and implications for hail growth. J. Atmos. Sci., 44, 2060-2073, https://doi.org/10.1175/1520-0469(1987)044<2060:THMSEH> 2.0.CO;2.

Orf, L., R. Wilhelmoson, B. Lee, C. Finley, and A. Houston, 2017: Evolution of a long-track violent tornado within a simulated supercell. Bull. Amer. Meteor. Soc., 98, 45-68, https://doi.org/ 10.1175/BAMS-D-15-00073.1.

Ortega, K. L., 2018: Evaluating multi-radar, multi-sensor products for surface hail-fall diagnosis. Electron. J. Severe Storms Meteor., 13 (1), https://ejssm.org/ojs/index.php/ejssm/article/ viewArticle/163

Peters, J. M., C. J. Nowotarski, and H. C. Morrison, 2019: The role of vertical wind shear in modulating maximum supercell 
updraft velocities. J. Atmos. Sci., 76, 3169-3189, https:// doi.org/10.1175/JAS-D-19-0096.1.

Picca, J. C., and A. V. Ryzhkov, 2012: A dual-wavelength polarimetric analysis of the 16 May 2010 Oklahoma City extreme hailstorm. Mon. Wea. Rev., 140, 1385-1403, https://doi.org/ 10.1175/MWR-D-11-00112.1.

Potvin, C. K., D. Betten, L. J. Wicker, K. L. Elmore, and M. I. Biggerstaff, 2012a: 3DVAR versus traditional dual-Doppler wind retrievals of a simulated supercell thunderstorm. Mon. Wea. Rev., 140, 3487-3494, https://doi.org/10.1175/MWR-D-12-00063.1.

_ - L. J. Wicker, and A. Shapiro, 2012b: Assessing errors in variational dual-Doppler wind syntheses of supercell thunderstorms observed by storm-scale mobile radars. J. Atmos. Oceanic Technol., 29, 1009-1025, https://doi.org/10.1175/ JTECH-D-11-00177.1.

Pruppacher, H. R., and R. M. Rasmussen, 1979: A wind tunnel investigation of the rate of evaporation of large water drops falling at terminal velocity in air. J. Atmos. Sci., 36, 1255-1260, https:// doi.org/10.1175/1520-0469(1979)036<1255:AWTIOT>2.0.CO;2.

_ and J. D. Klett, 1997: Microphysics of Clouds and Precipitation. 2nd ed. Kluwer Academic, 954 pp.

Púčik, T., P. Groenemeijer, D. Rýva, and M. Kolář, 2015: Proximity soundings of severe and nonsevere thunderstorms in central Europe. Mon. Wea. Rev., 143, 4805-4821, https:// doi.org/10.1175/MWR-D-15-0104.1.

Rädler, A., P. Groenemeijer, E. Faust, and R. Sausen, 2018: Detecting severe weather trends using an additive regressive convective hazard model (AR-CHaMo). J. Appl. Meteor. Climatol., 57, 569-587, https://doi.org/10.1175/JAMC-D-17-0132.1.

Rasmussen, R. M., and A. J. Heymsfield, 1985: A generalized form for impact velocities used to determine graupel accretional densities. J. Atmos. Sci., 42, 2275-2279, https://doi.org/10.1175/ 1520-0469(1985)042<2275:AGFFIV>2.0.CO;2.

_ and _ 1987a: Melting and shedding of graupel and hail. Part I: Model physics. J. Atmos. Sci., 44, 2754-2763, https://doi.org/ 10.1175/1520-0469(1987)044<2754:MASOGA >2.0.CO;2.

__ , and __, 1987b: Melting and shedding of graupel and hail. Part III: Investigation of the role of shed drops as hail embryos in the 1 August CCOPE severe storm. J. Atmos. Sci., 44, 2783-2803, https://doi.org/10.1175/1520-0469(1987) 044<2783:MASOGA $>2.0$. CO;2.

Rotunno, R., J. B. Klemp, and M. L. Weisman, 1988: A theory for strong, long-lived squall lines. J. Atmos. Sci., 45, 463-485, https:// doi.org/10.1175/1520-0469(1988)045<0463:ATFSLL>2.0.CO;2.

Ryzhkov, A. V., M. R. Kumjian, S. M. Ganson, and A. P. Khain, 2013a: Polarimetric radar characteristics of melting hail. Part I: Theoretical simulations using spectral microphysical modeling. J. Appl. Meteor. Climatol., 52, 2849-2870, https:// doi.org/10.1175/JAMC-D-13-073.1.

$-, \ldots,-$, and P. Zhang, 2013b: Polarimetric radar characteristics of melting hail. Part II: Practical implications. J. Appl. Meteor. Climatol., 52, 2871-2886, https://doi.org/ 10.1175/JAMC-D-13-074.1.
Sazaki, G., S. Zepeda, S. Nakatsubo, M. Yokomine, and Y. Furukawa, 2012: Quasi-liquid layers on ice crystal surfaces are made up of two different phases. Proc. Natl. Acad. Sci. USA, 109, 1052-1055, https://doi.org/10.1073/pnas.1116685109.

Taszarek, M., H. E. Brooks, and B. Czernecki, 2017: Soundingderived parameters associated with convective hazards in Europe. Mon. Wea. Rev., 145, 1511-1528, https://doi.org/ 10.1175/MWR-D-16-0384.1.

Tessendorf, S. A., L. J. Miller, K. C. Wiens, and S. A. Rutledge, 2005: The 29 June supercell observed during STEPS. Part I: Kinematics and microphysics. J. Atmos. Sci., 62, 4127-4150, https://doi.org/10.1175/JAS3585.1.

Thorpe, A. J., M. J. Miller, and M. W. Moncrieff, 1982: Twodimensional convection in non-constant shear: A model of mid-latitude squall lines. Quart. J. Roy. Meteor. Soc., 108, 739-762, https://doi.org/10.1002/qj.49710845802.

Trapp, R. J., G. R. Marion, and S. W. Nesbitt, 2017: The regulation of tornado intensity by updraft width. J. Atmos. Sci., 74, 4199-4211, https://doi.org/10.1175/JAS-D-16-0331.1.

Tuttle, J. D., V. N. Bringi, H. D. Orville, and F. J. Kopp, 1989: Multiparameter radar study of a microburst: Comparison with model results. J. Atmos. Sci., 46, 601-620, https://doi.org/ 10.1175/1520-0469(1989)046<0601:MRSOAM>2.0.CO;2.

van Lier-Walqui, M., and Coauthors, 2016: On polarimetric signatures of deep convection for model evaluation: Columns of specific differential phase observed during MC3E. Mon. Wea. Rev., 144, 737-758, https://doi.org/10.1175/MWR-D-15-0100.1.

Wallace, R., K. Friedrich, B. Meier, W. Deierling, E. A. Kalina, P. T. Schlatter, and M. Serpas, 2018: Observing deep hail accumulations on the Colorado and Wyoming front range. 29th Conf. on Severe Local Storms, Stowe, VT, Amer. Meteor. Soc., 11.2, https://ams.confex.com/ams/29SLS/webprogram/ Paper348484.html.

Warren, R. A., H. Richter, H. A. Ramsay, S. T. Siems, and M. J. Manton, 2017: Impact of variations in upper-level shear on simulated supercells. Mon. Wea. Rev., 145, 2659-2681, https:// doi.org/10.1175/MWR-D-16-0412.1.

Weisman, M. L., and R. Rotunno, 2000: The use of vertical wind shear versus helicity in interpreting supercell dynamics. J. Atmos. Sci., 57, 1452-1472, https://doi.org/10.1175/15200469(2000)057<1452:TUOVWS > 2.0.CO;2.

Witt, A., N. D. Eilts, G. J. Stumpf, J. T. Johnson, E. D. Mitchell, and K. W. Thomas, 1998: An enhanced hail detection algorithm for the WSR-88D. Wea. Forecasting, 13, 286-303, https://doi.org/ 10.1175/1520-0434(1998)013<0286:AEHDAF > 2.0.CO;2.

, D. W. Burgess, A. Seimon, J. T. Allen, J. C. Snyder, and H. B. Bluestein, 2018: Rapid-scan radar observations of an Oklahoma tornadic hailstorm producing giant hail. Wea. Forecasting, 33, 1263-1282, https://doi.org/10.1175/WAF-D-18-0003.1.

Ziegler, C. L., P. S. Ray, and N. C. Knight, 1983: Hail growth in an Oklahoma multicell storm. J. Atmos. Sci., 40, 1768-1791, https://doi.org/10.1175/1520-0469(1983)040<1768:HGIAOM> 2.0.CO;2. 